\title{
CES
}

COOPERATIVISMO E ECONOMÍA SOCIAL

Núm. 43 (2020-2021), páxs. 57-95

ISSN: 2660-6348

\section{CONCEITO JUSNORMATIVO EUROPEU DE EMPRESA SOCIAL: A ENGENHARIA UTILIZADA NA CONSTRUÇÃO DO CONCEITO}

\section{EUROPEAN NORMATIVE LEGAL CONCEPT OF SOCIAL ENTERPRISE: ENGINEERING USED IN THE CONSTRUCTION OF THE CONCEPT}

\author{
Maíra Fajardo Linhares Pereira*
}

Recepción: 13/07/2021- Aceptación: 8/10/2021

\footnotetext{
* Professora Adjunta de Direito Empresarial da Universidade Federal de Juiz de Fora, doutoranda em Direito, Justiça e Cidadania no Século XXI na Universidade de Coimbra, Mestre em Direito Internacional e Integração Económica pela Universidade do Estado do Rio de Janeiro. Email: mairafajardolinharespereira@gmail.com. Endereço postal: Faculdade de Economia da Universidade de Coimbra, Av. Dias da Silva, 165, 3004-512, Coimbra.
} 


\section{RESUMO}

O tema deste artigo é o conceito jusnormativo europeu de empresa social, contudo o seu objeto não é este conceito em si, mas sim o seu processo de construção. O objetivo deste trabalho é, portanto, abordar o processo de construção desse conceito. Quanto mais claro e preciso for este processo, mais seguro e eficaz será o conceito construído. De forma simplificada, conceitos jusnormativos são conceitos encontrados no contexto das normas jurídicas. Tais conceitos representados por palavras ou expressões, como é o caso de empresa social, não têm um significado prévio, ao contrário, têm seu significado determinado pela interpretação de seu uso nas normas nas quais as palavras e ou expressões que os representam aparecem. Sendo assim, a língua possui um papel muito importante no processo de construção de um conceito jusnormativo. Línguas não são neutras, elas carregam conceções e formas de pensar, elas são formadas e transformadas de acordo com as práticas e culturas das comunidades onde são faladas. Logo, a língua utilizada no processo de criação do direito da UE pode influenciar na construção dos conceitos jusnormativos deste direito. O processo de construção do conceito jusnormativo de empresa social na UE apresenta uma peculiaridade que é o fato de ser realizado em 24 línguas oficiais, o que significa a possibilidade da existência de diferentes conceções deste conceito nos Estados-Membros, de acordo com suas práticas e cultura, além claro, da possibilidade da existência de outras expressões serem utilizadas para a representação do conceito em construção. Para a realização desta análise, o artigo está dividido em duas partes. A primeira traz uma explicação geral do significado da expressão conceitos jusnormativos, esclarece quando sua identificação se torna necessária e porque este é o caso do conceito de empresa social no ordenamento jurídico europeu. A segunda traz um aprofundamento sobre estes conceitos no contexto da teoria do direito a fim de identificar funções, classificações e processos necessários para a sua identificação e aponta como este conhecimento pode ser útil para a regulação da empresa social no ordenamento jurídico europeu.

Palavras chave: empresas sociais; regulação; direito da União Europeia; conceito jurídico; conceito jusnormativo.

\section{ABSTRACT}

The subject of this article is the European normative legal concept of social enterprise. However, its object is not this concept itself but its construction process. The objective of this work is, therefore, to approach the construction process of this concept. The clearer and more precise this process, the safer and more effective the constructed concept will be. In a simplified way, normative 
legal concepts are concepts found in the context of legal norms. Such concepts represented by words or expressions, as in the case of social enterprise, do not have a previous meaning. What determines their meaning is the interpretation of the norms where the words and or expressions that represent them appear. Thus, language has a vital role in the process of constructing a normative concept. Languages are not neutral; they carry concepts and ways of thinking; they are formed and transformed according to the practices and cultures of the communities where they are spoken. Therefore, the language used in the creation process of the EU law can influence the construction of the normative concepts of this right. The process of constructing the normative legal concept of social enterprise in the EU has a peculiarity which is the fact that it is carried out in 24 official languages, which means the possibility of the existence of different conceptions of this concept in the member countries of the EU, according to their practices and culture, besides, of course, the possibility of the existence of other expressions being used to represent the concept under construction. For this analysis, the article is divided into two parts. The first part provides a general explanation of the meaning of normative legal concepts, clarifies when its identification becomes necessary and why this is the case of the social enterprise concept in the European legal system. The second part provides an in-depth look at these concepts in the context of legal theory, exploring functions, classifications and processes necessary for their identification and points out how this knowledge can help regulate social business in the European legal system.

KEYWORLDS: social enterprises; regulation; European Union Law; legal concept; legal normative concept. 
SUMÁRIO: 1. NOTAS INTRODUTÓRIAS. 2 CONCEITOS NORMATIVOS E CONCEITOS TEÓRICOS. $2.1 \mathrm{O}$ que são conceitos jusnormativos e quando é necessário identificá-los? 2.2. Por que é preciso identificar o conceito jusnormativo europeu de empresa social? 2.3 Os EM possuem a mesma conceção do conceito de empresa social? 2.4 Quais tipos de conceitos jusnormativos foram adotados pelos EM? 3 A ENGENHARIA DA CONSTRUÇÃO DOS CONCEITOS JUSNORMATIVOS. 3.1 Os conceitos jurídicos diferem dos conceitos das outras ciências? 3.2. Conceitos jusnormativos são conceitos jurídicos? 3.3 Quando um conceito se converte em um conceito jusnormativo? 3.4 A UE já possui um conceito jusnormativo de empresa social? 3.5 Como determinar o conceito jusnormativo europeu de empresa social? 3.6 Quais são os elementos relevantes para o conceito jusnormativo de empresa social? 3.7 Qual a aplicabilidade de um conceito jusnormativo europeu de empresa social? 4 CONSIDERAÇÕES FINAIS 5 BIBLIOGRAFIA.

SUMMARY: 1 INTRODUCTORY NOTES. 2 NORMATIVE CONCEPTS, AND THEORETICAL CONCEPTS. 2.1 What are normative legal concepts, and when is it necessary to identify them? 2.2. Why is it necessary to identify the European legal normative concept of social enterprise? 2.3 Do MS have the same conception of the concept of social enterprise? 2.4 What types of normative legal concept MS have adopted? 3 THE ENGINEERING OF THE CONSTRUCTION OF NORMATIVE LEGAL CONCEPTS. 3.1 Do legal concepts differ from those of other sciences? 3.2. Are normative legal concepts a species of legal concepts? 3.3 When does a concept become a normative legal concept? 3.4 Does the EU already have a normative legal concept of social enterprise? 3.5 How to determine the European normative legal concept of social enterprise? 3.6 What are the relevant elements for the normative legal concept of social enterprise? 3.7 What is the applicability of a European normative legal concept of social enterprise? 4 FINAL CONSIDERATIONS 5 BIBLIOGRAPHY

\section{NOTAS INTRODUTÓRIAS}

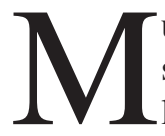

uito se discute sobre as empresas sociais, sobre sua importância e sobre sua regulação pelo Direito. Um passo indispensável para a sua regulação é o conhecimento do seu conceito jusnormativo. Aqui, interessa especialmente o conceito jusnormativo europeu de empresa social. Trata-se este de um conceito em construção. Em qualquer construção, seja de um edifício, seja de um conceito jusnormativo, conhecimentos de engenharia mais do que bemvindos, são mesmo necessários. O objetivo deste trabalho é, portanto, abordar o processo de construção do conceito jusnormativo europeu de empresa social. Acredita-se que quanto mais claro e preciso for este processo, mais seguro e eficaz será o conceito construído.

Este trabalho está dividido em duas partes. A primeira traz uma explicação geral do significado da expressão conceito jusnormativo utilizada neste trabalho, esclarece quando sua identificação se torna necessária e porque este é o caso do 
conceito de empresa social no ordenamento jurídico europeu. A segunda traz um aprofundamento sobre este conceito no contexto da teoria do direito a fim de identificar suas funções, suas classificações e os processos necessários para a sua identificação e aponta como este conhecimento pode ser útil para a regulação da empresa social no ordenamento jurídico europeu.

\section{Conceitos JuSNORMATIVOS}

\subsection{O que são conceitos jusnormativos e quando é necessário identificá-los?}

Os conceitos jusnormativos são conceitos jurídicos. Os conceitos exercem um papel central no Direito porque, de certa forma, todos os ordenamentos jurídicos são elaborados com a ajuda de palavras e termos que expressam conceitos ${ }^{1}$. Estudos baseados em conceitos jurídicos podem seguir diferentes perspetivas, a depender do objetivo. No caso deste trabalho, o objetivo é especificar o significado da expressão empresa social usada no ordenamento jurídico europeu. Sendo assim, o trabalho optou pela expressão conceito jusnormativo por dar a entender que se trata de um conceito encontrado no contexto das normas jurídicas. O entendimento do conceito jusnormativo adotado é semelhante à conceção de conceitos jurídicos (legal concepts) de Sartor ${ }^{2}$, que é mais explorada na segunda parte.

Este trabalho fundamenta-se também na perceção do Direito como uma prática argumentativa de acordo com a teoria do direito como integridade, elaborada por Dworkin ${ }^{3}$. Sendo assim, entende-se que o processo de elaboração do direito tem como condição a existência de uma língua comum pelos participantes do discurso. Logo, a princípio, os conceitos são pressupostos e não são discutidos, porque isto não é necessário, uma vez que todos os participantes do discurso compartilham conceito e conceção das palavras e expressões utilizadas. Quando assim, a elaboração e a aplicação de normas jurídicas ocorrem de maneira fluida. A necessidade de discussão e identificação de um conceito jusnormativo ocorre quando os participantes do discurso possuem conceções ${ }^{4}$ diferentes de um determinado conceito.

Os participantes de um discurso costumam partilhar conceitos e conceções em um processo discursivo quando usam não somente a mesma língua, mas também, a mesma linguagem. Ou seja, todas as partes envolvidas conhecem as palavras

HAGE, J. C. \& PFORDTEN, D. von der (eds.), Concepts in Law, Springer, 2009, Introduction.

2 SARTOR, G. «Understanding and Applying Legal Concepts: An Inquiry on Inferential Meaning», in J. C. Hage \& D. von der Pfordten (eds.), Concepts in Law, Springer, 2009.

3 DWORKIN, R. O Império do Direito. Martins Fontes, São Paulo, 2003.

4 POSCHER, R. «The Hand of Midas: When Concepts Turn Legal, or Deflating the Hart-Dworking Debate», in J. C. Hage \& D. von der Pfordten (eds.), Concepts in Law, Springer, 2009. 
usadas, seus sentidos denotativos, as regras gramaticais, e mais do que isto, compartilham o mesmo contexto histórico-cultural e sabem usar estas palavras e regras para expressar seus sentimentos e opiniões e compreender os sentimentos e as opiniões das demais partes envolvidas. Isto é o que costuma acontecer quando o discurso se dá entre os membros de uma mesma comunidade, que partilham as mesmas práticas, a mesma cultura e a mesma história.

Contudo, ocorre, às vezes, de surgirem no discurso jurídico palavras ou expressões cujo sentido não seja compartilhado, ou sequer, sejam conhecidas por todas as partes. Logo, o esclarecimento do significado desta palavra ou expressão se torna necessário como condição para a continuidade do discurso. Isto sobrevém, por exemplo, quando esta palavra ou expressão é nova no discurso jurídico, ou porque expressa uma nova prática surgida na comunidade e ainda não regulada pelo direito ou porque se trata de alguma expressão técnica pertencente a outra área do conhecimento. A confusão pode ser ainda maior se a expressão em causa for formada por palavras, de certa forma, corriqueiras, mas comumente utilizadas com diferentes sentidos.

\subsection{Por que é preciso identificar o conceito jusnormativo europeu de empresa social?}

O caso da expressão empresa social parece se enquadrar em todas as situações mencionadas.

Trata-se de uma expressão relativamente nova nos ordenamentos jurídicos. As primeiras referências à expressão empresa social identificada com o conceito discutido neste trabalho remetem ao final dos 1980 e início dos anos 1990 na Europa e nos Estados Unidos. Nos Estados Unidos foi lançada em 1993 a social enterprise initiative, pela Harvard Business School ${ }^{5}$. Na Europa foi a criada a EMES International Research Network em 1996, cujo nome advém do seu primeiro projeto de pesquisa cujo título original em francês era L'EMergence de l'Entreprise Sociale en Europe e realizado entre 1996 e $2000^{6}$. Já nos ordenamentos, a primeira lei apontada como voltada para as empresas sociais foi a Legge 8 novembre 1991, n. 381, aprovada pelo Parlamento italiano e responsável por atribuir um estatuto específico para as cooperativas sociais. Embora as cooperativas sociais fossem consideradas empresas sociais, a expressão impresa sociale não consta no texto da lei. Já na UE, a primeira vez que a expressão foi utilizada em um regulamento (ato legislativo integralmente obrigatório e diretamente aplicável em todos os EstadosMembros (EM) foi no Regulamento (UE) 346/2013 do Parlamento Europeu e do

\footnotetext{
5 DEFOURNY, J. «Empresa social», Dicionário Internacional da Outra Economia, coord. de A. D. Cattani, J.-L. Laville, L. I. Gaiger, \& P. Hespanha, Almedina, Coimbra, 2009, pág. 188-192 (188).

6 EMES - International Research Network (EMES) (n.d). Who we are. Consultado em 6 out. 2021. Disponível em: https://emes.net/who-we-are/.
} 
Conselho de 17 de abril de 2013 relativo aos fundos europeus de empreendedorismo social, embora tenha sido mencionada anteriormente em outros atos adotados pelas instituições e outras entidades da UE, com destaque para a Comunicação da Comissão ao Parlamento Europeu, ao Conselho, ao Comité Económico e Social Europeu e ao Comité das Regiões, de 25 de outubro de 2011, intitulada «Iniciativa de Empreendedorismo Social - Construir um ecossistema para promover as empresas sociais no centro da economia e da inovação sociais» (COM(2011) 682 final), agora em diante IES, que se tornou a principal ${ }^{7}$ fonte de referência para o conceito de empresa social no direito da UE.

Trata-se também de uma expressão utilizada em outras áreas do conhecimento, de acordo com os projetos de pesquisa mencionados anteriormente.

Trata-se ainda de uma expressão formada por palavras corriqueiras, mas comumente usadas com sentidos diferentes.

Ao caso da expressão empresa social acresce-se o fato de ambas palavras formadoras da expressão serem de uso frequente no discurso jurídico. Mas, como adverte Coutinho de Abreu, ambas palavras são polissêmicas e possuem significados algo indeterminados, sendo o uso da palavra social no discurso jurídico "pouco denotativo e difusamente conotativo", enquanto a palavra empresa "designa fenómenos vários, de harmonia com os diversos contextos jurídico-problemáticos, sistemático-funcionais e local-temporais" ${ }^{8}$.

Se o discurso sobre a regulação das empresas sociais já enfrenta esta dificuldade no âmbito dos EM, a dificuldade é ainda maior no âmbito europeu. Isto, porque, ainda que o debate ocorra entre os membros de uma mesma comunidade, a UE, esta não possui uma língua única, mas sim $24^{9}$ línguas oficiais, pois sendo uma comunidade formada por outras comunidades, possui as línguas de todas elas.

É claro que durante um discurso feito por participantes que não compartilham a mesma língua, uma língua dominada por todos é escolhida para ser utilizada, mas isto não garante que todos a estejam utilizando da mesma forma, isto é, todos podem usar a mesma língua, mas não necessariamente a mesma linguagem.

Neste tipo de discurso, se para alguns dos participantes a língua escolhida é a sua língua nativa, o mesmo não ocorre para outros. Sendo assim, um dos recursos

\footnotetext{
7 Fici aponta a influência do que ele chama de definição operacional da IES (FICI, A. A European Statute for Social and Solidarity-Based Enterprise: Study for the Juri Committee. European Parliament, 2017, pág. 6).

8 ABREU, J. M. Coutinho de, «Empresas Sociais (Nótulas de Identificação)», CES, 37, (2015), pág. 369-376 (371).

9 Mesmo após a saída do Reino Unido, o inglês continua a ser uma das línguas oficiais da UE por ser língua oficial da Irlanda e de Malta. UNIÃO EUROPEIA (UE) (n.d). As línguas da União Europeia. Consultado em 3 jun. 2021. Disponível em: https://europa.eu/european-union/about-eu/ eu-languages_pt.
} 
utilizados é a tradução. O problema é que a tradução pode ser feita levando em consideração somente o significado literal, denotativo de uma palavra ou expressão, ignorando as diferenças socio-histórica-culturais existentes entre as comunidades particulares dos participantes, o que pode gerar confusões na compreensão, dificultando o desenvolvimento do discurso.

O que ocorre nestas situações é que apesar de os participantes compartilharem a mesma língua, e, portanto, fazerem uso de uma mesma expressão, podem possuir conceções diferentes sobre o significado desta expressão. Pode-se dizer, assim, que compartilham conceitos, no sentido de reconhecerem a existência deste, mas não compartilham conceções, em outras palavras, têm intenções diferentes ${ }^{10}$.

Se o desentendimento é possível de ocorrer entre participantes falantes de apenas duas línguas diferentes, é mais fácil ainda entre os participantes falantes de 24 línguas diferentes, como é o caso da UE. De acordo com o multilinguismo, um dos princípios fundadores da UE e consagrado na Carta dos Direitos Fundamentais, todas as pessoas têm o direito de usar qualquer uma das línguas oficiais para se dirigir às instituições da UE, devendo obter uma resposta na mesma língua; no Parlamento Europeu (PE), os deputados podem exprimir-se em qualquer uma das línguas; e em todas as reuniões do Conselho Europeu e do Conselho da União Europeia há interpretação para todas as línguas. Este mesmo princípio garante ainda que todo o direito da UE deve ser publicado em todas as línguas com exceção do irlandês ${ }^{11}$.

Sem prejuízo ao multilinguismo, a Comissão Europeia (CE) gere suas atividades internas em três línguas processuais, inglês, francês e alemão ${ }^{12}$. Embora eurodeputados possam falar em qualquer uma das línguas oficiais no PE, a língua mais usada em 2012 foi o inglês. Isto se deve provavelmente ao fato de todos os representantes da CE falarem inglês e os conteúdos legislativos serem escritos em inglês. O uso majoritário do inglês parece ser uma tendência a ser mantida porque é, em geral, a segunda língua da maioria das pessoas ${ }^{13}$.

Um dos recursos oferecidos pela UE para facilitar o trabalho de tradutores e também para servir a todos os funcionários da UE e ao público em geral é a base de dados denominada IATE (Interactive Terminology for Europe) que contém,

${ }_{10}$ POSCHER, R. «The Hand of Midas: When Concepts Turn Legal, or Deflating the Hart-Dworking Debate», in J. C. Hage \& D. von der Pfordten (eds.), Concepts in Law, Springer, 2009, 1 Concepts and Conceptions.

${ }_{11}$ União Europeia (UE). As línguas da União Europeia. Consultado em 3 jun. 2021. Disponível em: https://europa.eu/european-union/about-eu/eu-languages_pt.

${ }^{12}$ Comissão Europeia (CE) (2013). Memo - Perguntas frequentes sobre línguas na Europa. Consultado em 3 jun. 2021. Disponível em: https://ec.europa.eu/commission/presscorner/detail/en/MEMO_13_825.

13 CODREA-RADO, A. «European parliament has 24 official languages, but MEPs prefer English», THE GUARDIAN, (2014). Consultado em 4 jun. 2021. Disponível em: https://www.theguardian. com/education/datablog/2014/may/21/european-parliament-english-language-official-debates-data. 
em sua versão pública, todas as línguas oficias da UE. A IATE contém a definição de termos usados nos documentos da UE. Não se trata de um dicionário, mas de uma base de dados baseada em conceitos, um mesmo termo pode ter mais de uma entrada se representar conceitos diferentes ${ }^{14}$.

A IATE é uma ferramenta cujas definições auxiliam o trabalho de tradutores e a compreensão do público em geral dos textos da UE, mas é importante saber que não são conceitos normativos, no entanto, podem ter algum papel na construção destes conceitos.

No caso da empresa social, na entrada em português, a definição presente na IATE tem como referência a IES, publicada em 2011. Como visto, a IES é a principal fonte de referência para o conceito de empresa social no direito da UE, contudo, como afirmado na própria comunicação, a Comissão Europeia (CE), não apresentou "uma definição normativa" de empresa social, mas sim propôs, antes, "uma descrição" desta ${ }^{15}$.

Já na entrada em inglês, a definição presente na IATE tem como referência a publicação do Comité Económico e Social Europeu (CESE) resultado do projeto Social Enterprise Project intitulada 'EESC recommendations on Social Enterprise' de 2014. O CESE, neste documento, adotou o mesmo posicionamento da CE, afirmando que entende que uma definição clara é necessária, mas que em vez de uma definição, preferiu adotar uma descrição já proposta em trabalhos próprios anteriores ${ }^{16}$.

Apesar da adoção de diferentes referências para a definição em português e inglês, as definições propostas na IATE são muito semelhantes entre si. Ambas afirmam que as empresas sociais têm os objetivos sociais como principal objetivo e não a geração de $\operatorname{lucros}^{17}$, sem aprofundar em outras características destas empresas.

Ao buscar ${ }^{18}$ empresa social escolhendo português como língua de partida e inglês como língua de chegada, a IATE mostra social enterprise como correspondente, e inclui também o termo empresa de economia social em português e os termos social economy enterprise e social business em inglês. Para a IATE não

${ }_{14}$ Interactive Terminology for Europe (IATE) (2021). Perguntas frequentes sobre a IATE. Consultado em 3 jun 2021. Disponível em: https://iate.europa.eu/faq.

$15 \mathrm{COM}(2011) 682$ final, pág. 4.

16 European Economic and Social Committee (EESC) (2014). Project on Social Enterprise Recommendations (ISBN 978-92-830-2535-1), Bruxelles, pág. 2.

17 Definição em português: "Empresa cujo objectivo principal é ter uma incidência social, mais do que gerar lucros para os seus proprietários ou parceiros." Definição em inglês: "entity that is aimed primarily at producing social benefits that serve the general public or certain social groups, chiefly on a not-for-profit basis." Consulta realizada no website da IATE no dia 03.06.2021.

18 Resultados encontrados em consulta realizada no website da IATE no dia 03.06.2021. 
existe um correspondente em português para este último termo, apesar de eventualmente este termo poder ser traduzido como negócios sociais. As definições na IATE podem ser acompanhadas de uma nota do nível da língua. No caso do termo empresa social a nota em português traz a observação de que "parece haver uma distinção entre empresa social e empresa de economia social dado que muitas empresas sociais não são da economia social". Já na nota em inglês, a observação parece ser em sentido contrário, ao afirmar que o termo social enterprise às vezes é usado de forma intercambiável com social and solidarity-based enterprises ${ }^{19}$.

Os dados sobre as línguas processuais da UE e sobre a língua mais usada são relevantes para a definição e para a compreensão dos conceitos jusnormativos do direito da UE. Línguas não são neutras, elas carregam conceções e formas de pensar, elas são formadas e transformadas de acordo com as práticas e culturas das comunidades onde são faladas. Logo, a língua utilizada no processo de criação do direito da UE pode influenciar na construção dos conceitos jusnormativos deste direito. A consulta ao termo empresa social realizado na IATE exemplifica bem esta condição das línguas.

A existência de perceções diferentes pode ocorrer em momentos distintos no desenvolvimento do direito da UE. Um conceito relevante, por exemplo, pode ser percebido de formas diferentes pelos participantes envolvidos diretamente na elaboração de um documento legal, que, caso percebam isto, poderão acordar em uma conceção para ser usada neste documento, de forma expressa. Mas a existência de perceções diferentes pode ocorrer também no momento da realização das traduções. Neste momento, pode ser um pouco mais difícil identificar a ocorrência destas e documentos com conceitos percebidos de forma diferente em diversas línguas podem ter sua aplicação afetada. Apesar de parecer, a princípio, limitador, a adoção de conceitos jusnormativos expressos poderia colaborar para o trabalho de tradução e aplicação do direito da UE.

Regular uma nova prática pode significar a inclusão de novos conceitos jusnormativos no direito da UE e o novo conceito pode ser percebido de modo diverso pelos membros das diferentes comunidades particulares que integram a maior comunidade, a UE. A regulação da nova prática será, no entanto, mais efetiva quanto mais similares forem a conceção adotada na regulamentação europeia e a conceção das comunidades particulares.

\footnotetext{
19 Fici aponta que seja provável o uso da expressão social and solidarity-based social enterprises seja entendida como sinônima de social enterprise devido ao uso da expressão entreprises de l'économie sociale et solidaire usada na legislação francesa (Lei n. ${ }^{\circ} 2014 / 856$ de 31 de julho) (FICI, A. A European Statute for Social and Solidarity-Based Enterprise: Study for the Juri Committee. European Parliament, 2017, pág. 8). No entanto, no IATE a expressão entreprises de l'économie sociale et solidaire não é apontada entre as correspondências com empresa social, aparecendo somente na nota do nível de língua como sendo empresas distintas das empresas sociais devido ao seu modo de gestão democrático e participativo.
} 
A adoção de um conceito jusnormativo pelo direito da UE, diante da existência de diferentes conceções deste conceito pelos EM, deve ser compatível com todas elas. A questão é, seja um conceito jusnormativo expresso ou implícito, este conceito sempre implicará a adoção de uma conceção, que pode ser mais ou menos similar a dos EM. A opção pela não elaboração de um conceito expresso pode parecer, a princípio, mais compatível com o respeito à liberdade dos EM, mas esta opção pode acabar tendo um efeito contrário.

\subsection{Os EM possuem as mesmas conceções do conceito de empresa social?}

Em vários EM não somente a prática da empresa social está presente, como também a regulação jurídica desta já foi iniciada. Esta regulação busca apreender a prática tal como ela é para a comunidade local, assim como busca integrá-la no contexto dos conceitos e da regulação já existente. Este trabalho de interpretação e contextualização da realidade requer conhecimento e respeito às práticas, à cultura, à história da comunidade e ao seu ordenamento jurídico. É exatamente ao observar a situação em cada Estado-membro é que se pode perceber o uso de uma mesma expressão, empresa social, com conceções diferentes. Ou seja, os EM compartilham um conceito, mas não compartilham conceções.

Meira e Ramos ${ }^{20}$, explicitam bem este ponto ao afirmarem que "(n)o contexto da União Europeia, a disciplina jurídica em matéria de empresas sociais é uma regulação de fonte nacional e não harmonizada". As autoras destacam, contudo que esta falta de harmonização não obsta que a UE tenha desenvolvido, através de iniciativas de seus órgãos, vários documentos relacionados às empresas sociais. Parafraseando as autoras, pode-se dizer que na UE convivem diferentes conceções de empresa social, a conceção desenvolvida por seus órgãos com as conceções normativas vigentes nos ordenamentos jurídicos nacionais.

O processo de regulação de uma nova prática envolve a sua classificação no arcabouço normativo preexistente. Este trabalho de classificação consiste em identificar as características principais da nova prática a fim de incluí-la em uma das áreas do direito para depois então relacioná-la a um dos códigos, estatutos ou lei de bases desta área.

No documento considerado referência no tema da empresa social na UE, IES, a Comissão considerou a empresa social como um "agente da economia social"21.

A princípio esta afirmação pode induzir a compreensão de ser a conceção europeia semelhante às conceções dos EM que também classificaram a empresa social como um agente da economia social. Ocorre que economia social também

${ }^{20}$ MEIRA, D., \& RAMOS, M. E. «Empresas sociais e sociedades comerciais: ¿realidades convergentes ou divergentes?». COOPERATIVISMO \& DESARROLLO, 27, 1 (2019), pág.1-33 (4).

$21 \operatorname{COM}(2011) 682$ final, pág. 2. 
é um conceito jusnormativo, o que leva à indagação se a UE e os EM possuem conceções correspondentes deste conceito.

A resposta a esta indagação é negativa porque apesar de ser um conceito presente em quase todos os EM, é um conceito com conceções diferentes.

Como prática, a economia social remonta às formas mais antigas de associações humanas e teve suas principais expressões na Europa ao longo do século $\mathrm{XIX}^{22}$, o seu conceito, contudo, desenvolvido no início do século XXI, parece estar diretamente relacionado aos conceitos jusnormativos desenvolvidos pelos EM.

Em geral, os EM parecem optar entre duas opções ou por uma combinação destas. Ou o conceito jusnormativo baseia-se na identificação das formas jurídicas da maioria das iniciativas da economia social, como cooperativas, mutualidades, associações e fundações; ou baseia-se na identificação dos traços comuns das organizações que ela agrupa, como finalidade e modo de organização. Portugal, por exemplo, na Lei de Bases da Economia Social (LBES), Lei n. ${ }^{\circ}$ 30/2013 de 8 de maio, optou pela combinação de critérios, subjetivo (baseado na forma jurídica) e objetivo (baseado na finalidade e no tipo de atividade) ${ }^{23}$.

Provavelmente a adoção de diferentes conceitos jusnormativos pelos EM deve-se às diferentes conceções do conceito de economia social de cada um, resultantes do desenvolvimento próprio das práticas associadas a este conceito em cada comunidade.

Não é preciso aprofundar o conceito jusnormativo de economia social da UE para concluir que este colide com o de alguns EM. Isto é percetível na IES e vale tanto para os EM possuidores de conceitos jusnormativos baseados nos critérios subjetivo ou objetivo. Chega-se a esta conclusão por um trabalho interpretativo da redação da IES.

Na IES, a CE afirma que o sector da economia social "engloba as entidades que têm um estatuto jurídico específico (cooperativas, fundações, associações, mútuas, etc.), (...) assim como as empresas sociais sob a forma de sociedade privada ou sociedade anónima tradicional”24.

Nesta afirmação, a CE destaca o critério subjetivo. O ponto de choque desta conceção de economia social com os conceitos jusnormativos de alguns EM é a presença das sociedades, especialmente das sociedades anônimas entre as entidades da economia social.

22 DEFOURNY, J. «Economia social». Dicionário Internacional da Outra Economia, coord. de A. D. Cattani, J.-L. Laville, L. I. Gaiger, \& P. Hespanha, Almedina, Coimbra, 2009, pág. 156-161 (156).

${ }^{23}$ MEIRA, D., \& RAMOS, M. E. «Empresas sociais e sociedades comerciais: ¿realidades convergentes ou divergentes?». COOPERATIVISMO \& DESARROLLO, 27, 1 (2019), pág.1-33 (3).

${ }^{24} \operatorname{COM}(2011) 682$ final, pág. 3. 
Em Portugal, por exemplo, ainda há dúvida sobre esta questão legal. Meira e Ramos expõem de forma clara esta controvérsia. Isto ocorre porque a LBES não incluiu expressamente as sociedades no rol das entidades da economia social previsto em seu artigo $4^{\circ}$, mas deixou esta possibilidade em aberto na alínea $\mathrm{h}$ ) ao afirmar que outras entidades podem integrar o setor desde que tenham personalidade jurídica, respeitem os princípios orientadores da economia social e constem da base de dados deste setor, dividindo, portanto, a opinião da doutrina portuguesa. $\mathrm{O}$ argumento daqueles não favoráveis à possibilidade de inclusão das sociedades comerciais fundamenta-se na própria legislação portuguesa que em sua definição genérica de sociedade prevista no artigo 980 do Código Civil (CCiv) prevê como objetivo desta a obtenção de lucros e sua distribuição entre os sócios. O outro lado, o dos favoráveis à possibilidade de inclusão das sociedades entre as entidades da economia social, usa a alínea g) do artigo 5. ${ }^{\circ}$ da LBES, que prevê os princípios orientadores do setor para fundamentar seu argumento. A alínea em questão fala em afetação e distribuição dos excedentes, devendo ser estes entendidos como resultados positivos, o que abrange os lucros. Esta interpretação leva a admissão da possibilidade de uma entidade da economia social prosseguir um fim lucrativo, oferecendo um contra-argumento para quem nega aquela possibilidade, ainda que incompleto, pois a permissão para prosseguir este fim não se estende à sua distribuição, considerada, por alguns, uma condição necessária para as sociedades ${ }^{25}$.

Os argumentos acima, como visto, focam nos conceitos jusnormativos baseados na opção subjetiva. Mas há outrossim argumentos baseados na opção objetiva que demonstram a colisão entre a conceção de economia social da UE e as de alguns EM. Na IES, a CE, afirma que as empresas sociais são agentes da economia social e que os estatutos jurídicos específicos da economia social são particularmente adaptados às empresas sociais, isto porque entende que o modo de organização destas baseia-se em princípios democráticos ou participativos ${ }^{26}$. A questão controversa aqui no caso da possibilidade de admissão das sociedades como entidades da economia social é o respeito a estes princípios. Isto porque em alguns ordenamentos jurídicos a regulação das sociedades implica uma organização apoiada no capital e não nas pessoas.

A dúvida sobre a possibilidade da inclusão das sociedades entre as entidades da economia social em Portugal persiste se levada em consideração a opção objetiva para o desenvolvimento do seu conceito jusnormativo. Além da exigência do lucro subjetivo (distribuição), há outros fatores conflituantes com os traços comuns das entidades do setor relacionados à finalidade da atividade e aos modos

${ }^{25}$ MEIRA, D., \& RAMOS, M. E. «Empresas sociais e sociedades comerciais: ¿realidades convergentes ou divergentes?». COOPERATIVISMO \& DESARROLLO, 27, 1 (2019), pág.1-33 (17-22).

${ }^{26} \mathrm{COM}(2011) 682$ final, pág. 3. 
de organização que dificultam a inclusão das sociedades, como a falta de democraticidade na gestão, especialmente nas sociedades anônimas; a irrelevância do caráter pessoal; o seu intuito egoístico; e o caráter circunstancial e voluntário de suas políticas de responsabilidade social ${ }^{27}$.

Pelo exposto, pode-se constatar que o conceito jusnormativo de empresa social possui uma relação direta com o conceito jusnormativo de economia social, tanto no âmbito europeu, quanto no âmbito dos EM. A regulação da empresa social exige a sua classificação dentro do arcabouço jurídico preexistente. A existência de uma relação entre as empresas sociais e a economia social é inegável, mas é inegável também que as empresas sociais apresentam alguns pontos em comum com as empresas capitalistas. A perceção de uma maior proximidade com as empresas da economia social ou com as empresas da economia de mercado é um dos fatores condicionantes da forma de regular as empresas sociais. Ainda que os sistemas jurídicos, europeu e nacionais, sejam únicos e ao final orientados pelos princípios fundamentais de cada um, as diversas classificações e subclassificações internas possuem princípios e regras próprios.

A própria relevância da questão de ser a empresa social uma empresa de economia social pode variar entre os EM, o exemplo da IATE é um indicativo. Em Portugal, cuja língua oficial é o português, a economia social é um conceito importante e as práticas e entidades associadas a ela são o resultado de um longo processo socioecónomico e de construção jurídica. Em Portugal, a expressão empresa social não é propriamente uma novidade, por muito tempo empresas sociais era um termo que poderia ser usado para identificar as empresas da economia social. Algumas características na descrição da IES, podem, por exemplo, não encontrar correspondência nas características das empresas da economia social de Portugal, por isso a nota do nível da língua na IATE. Já o Reino Unido, cuja língua oficial é o inglês, o conceito de economia social (social economy) não tem a mesma relevância e não recebeu o mesmo tratamento dado por Portugal. Talvez, por isso, a discussão, de serem as empresas sociais com as caraterísticas descritas na IES, por exemplo, o mesmo que empresas da economia social ou não, seja irrelevante para um debate realizado por falantes da língua inglesa, e por isso, a nota do nível da língua afirme que a expressão social solidarity-based enterprise às vezes é usada de forma intercambiável com a expressão empresa social.

Nos mais de 25 anos desde a elaboração da primeira lei específica na Itália em 1991 (Legge 8 novembre 1991, n. 381), mais e mais ordenamentos jurídicos passaram a regular as práticas associadas às empresas sociais. Na sequência da Itália adotaram normas consideradas específicas sobre as práticas associadas às empresas sociais na Europa, sem necessariamente mencionar a expressão na lín-

\footnotetext{
${ }^{27}$ MEIRA, D., \& RAMOS, M. E. «Empresas sociais e sociedades comerciais: ¿realidades convergentes ou divergentes?». COOPERATIVISMO \& DESARROLLO, 27, 1 (2019), p.1-33 (28).
} 
gua nacional correspondente a empresa social, por exemplo, Portugal em 1998; Espanha em 1999; França em 2001; Finlândia em 2003; Reino Unido em 2005; Dinamarca em $2014^{28}$.

\subsection{Quais os tipos de conceitos jusnormativos foram adotados pelos EM?}

Apesar de cada Estado ter optado por formas diferentes de regulação, é possível observar duas tendências distintas para a regulamentação das práticas associadas às empresas sociais ao longo dos anos ${ }^{29}$. Alguns EM optaram por introduzir normas que não regulam expressamente a empresa social, mas sim novos tipos legais, em geral novos tipos de cooperativas que apresentavam uma forma de organização e objetivos normalmente associados ao conceito de empresa social. Este foi o caso, por exemplo, da Itália que regulamentou a chamada cooperativa social (Legge 8 novembre 1991, n. 381); de Portugal que regulamentou as denominadas cooperativas de solidariedade social (Decreto-Lei n. ${ }^{\circ}$ 7/98 de 15 de Janeiro); da Espanha que regulamentou o que intitulou de cooperativas de iniciativa social (Ley 27/1999, de 16 de julio, de Cooperativas) e da França que regulamentou as cooperativas de interesse coletivo (Loi $n^{\circ} 2001-624$ du 17 juillet 2001 portant diverses dispositions d'ordre social, éducatif et culturel (1)). Mas há também o caso do Reino Unido que preferiu criar um novo tipo de sociedade, a community interest company (The Community Interest Company Regulations 2005). Outros EM optaram pela criação de um status legal passível de ser atribuído a diferentes tipos legais. A Itália, pioneira na regulação da empresa social, decidiu adotar também em 2006 o modelo baseado em um status legal (Decreto Legislativo 24 marzo 2006, n. 155), possibilitando o reconhecimento da condição de empresa social a outros tipos legais além das cooperativas. Este modelo baseado na criação de um status foi o escolhido pela Finlândia (Laki sosiaalisista yrityksistä 1351/2003) e pela Dinamarca (LOV nr 711 af 25/06/2014).

Paralelamente ao movimento regulador das empresas sociais na Europa, outros Estados passaram também a regular estas práticas. Pela influência exercida no mundo, devem ser mencionados os Estados Unidos que optaram por uma regulação das empresas sociais mais próxima à regulação das entidades da economia

28 European Commission (EC) (2015). A map of social enterprises and their ecosystems in Europe. Synthesis Report. Luxembourg: Publications Office of the European Union. Disponível em: https:// europa.eu/!Qq64ny, pág. 52-54.

29 European Commission (EC) (2015). A map of social enterprises and their ecosystems in Europe. Synthesis Report. Luxembourg: Publications Office of the European Union. Disponível em: https:// europa.eu/!Qq64ny, pág. 51. 
de mercado ${ }^{30}$ e instituíram a Low-Profit Limited Liability Company (L3C) ${ }^{31}$ a Social Purpose Corporation (SPC) ${ }^{32}$ e a Benefit Corporation, também denominada em alguns estados Public-Benefit Corporation ${ }^{33}$.

Pode-se dizer que estas duas tendências levaram ao desenvolvimento de duas espécies de conceitos jusnormativos de empresa social, como novo tipo legal ou como status legal ${ }^{34}$. A opção de cada Estado por uma ou outra espécie está diretamente relacionada às práticas identificadas como empresa social nas respetivas comunidades e às características de cada ordenamento jurídico. A escolha por um ou outro também não implica o reconhecimento da empresa social como um agente ou não da economia social.

A classificação de conceito jusnormativo vista apresenta duas espécies, mas há outro fator além deste com consequências significativas para a regulação das empresas sociais, a relação empresas sociais - sociedades comerciais. No caso do conceito jusnormativo da espécie tipo legal, a regulação das empresas sociais será diferente caso o tipo escolhido seja uma variante cooperativa ou societária, isto porque como visto cooperativas e sociedades comerciais têm diferentes objetivos e diferentes modos de organização e de gestão. Um exemplo das diferenças trazidas para a regulação está nas políticas e instrumentos de financiamento criados e regulamentados com o intuito de incentivar o desenvolvimento das empresas sociais. Instrumentos de private equity, por exemplo, atendem muito bem empresas sociais com formato de sociedades comerciais, mas não às com formato de cooperativas ou associações, entidades típicas da economia social.

Observa-se que a opção pelo tipo legal com formato cooperativo foi feita em países europeus com forte presença do movimento cooperativista e da regulação deste como prática integrante da economia social. Nos EUA, por exemplo, o conjunto de ações diferentes das ações tradicionais do mercado e do Estado é

\footnotetext{
30 Nos EUA este tipo de regulação é de competência de cada estado, sendo assim não há uma lei nacional, mas leis estaduais nos estados que adotarem estes tipos empresariais.

${ }_{31}$ Em 2021, 8 estados possuem legislação sobre a L3C (Americans for Community Development (n.d). Consultado em 7 de out. 2021. Disponível: https://americansforcommunitydevelopment.org/ laws/).

32 Ao final de 2015, os Estados de Washington, California, Florida e Minnesota haviam aprovado legislação sobre as SPCs (PAREKH, N. 51 Questions on Social Entrepeneurship, Mountain View, Quad Press, 2015, 3: Law and Policy - 18 What is a Social Purpose Corporation (SPC)?)

${ }_{33}$ Em 2021, 37 estados possuem legislação sobre a Benefit Corporation (Benefit Corporation (n.d). State by State Status of Legislation. Consultado em 7 de out. 2021. Disponível em: https://benefitcorp. net/policymakers/state-by-state-status).

34 Identificadas por Fici como "legal form of incorporation (either a particular type of cooperative or a particular type of company)" e legal qualification (or status)" (FICI, A. A European Statute for Social and Solidarity-Based Enterprise: Study for the Juri Committee. European Parliament, 2017, pág. 6).
} 
identificado como sector não lucrativo (non profit) ${ }^{35}$. Este sector inclui as organizações não lucrativas, mas exclui as cooperativas, devido a sua compreensão sobre o conceito de lucro, que considera os excedentes cooperativos como se fossem lucros ${ }^{36}$.

Economia social e terceiro sector são conceitos diferentes, apesar de serem usados algumas vezes como conceitos correspondentes, em comum, ambos têm a questão das empresas sociais como entidades pertencentes ou não a eles.

Para alguns pesquisadores, a empresa social possui um caráter inovador em relação tanto às entidades da economia social ou do terceiro sector quanto em relação às entidades da economia de mercado. Parte da inovação, em relação à economia social, estaria na forma de captação de recursos para o desenvolvimento das atividades e no seu carácter organizativo. Enquanto as organizações do setor não lucrativo obtém recursos principalmente de parcerias com o Estado e/ ou doações de particulares (pessoas físicas ou coletivas) e organizam-se predominantemente como organizações de trabalho voluntário e caráter caritativo, as empresas sociais buscam investidores, não doadores, organizam-se profissionalmente para serem autossustentáveis financeiramente, para isso, cobram pelos seus serviços e/ou produtos, e competem com as organizações tradicionais do mercado. As empresas sociais seriam assim, um híbrido das atividades lucrativas (for profit), pelas suas caraterísticas de organização, com as atividades não lucrativas (nonprofit), pelos seus objetivos, situando-se, portanto, entre o segundo setor (ou economia de mercado) e o terceiro setor (ou economia social), e por isso sendo também chamadas de setor $2,5^{37}$.

Este caráter híbrido das práticas associadas às empresas sociais, de um lado, $\mathrm{e}$ a existência de regulamentações bem delimitadas para as entidades da economia social e da economia de mercado, de outro, tornam o quadro legislativo em vigor inadequado para a regulação das empresas sociais, o que é uma das causas das diferentes regulações das empresas sociais nos diferentes Estados ${ }^{38}$.

Se pelos motivos acima já é difícil regular as empresas sociais em cada Estadomembro, a tarefa se torna mais difícil em nível europeu. Isto devido à necessidade de adoção de um conceito jusnormativo representativo das diferentes práticas re-

35 FERREIRA, S. «Terceiro sector». Dicionário Internacional da Outra Economia, coord. de A. D. Cattani, J.-L. Laville, L. I. Gaiger, \& P. Hespanha, Almedina, Coimbra, 2009, pág. 322-327 (322).

${ }^{36}$ NAMORADO, R. «O que é a economia social?». Economia Social em Textos, CECES, Coimbra, 2017, pág. 10-11.

37 ANAZ, S. (2014). «A inovação social aponta novos caminhos para as empresas». HSM MANAGEMENT, 103 (2014), pág. 58-72 (59).

${ }^{38}$ MEIRA, D., \& RAMOS, M. E. «Empresas sociais e sociedades comerciais: ¿realidades convergentes ou divergentes?». COOPERATIVISMO \& DESARROLLO, 27, 1 (2019), pág.1-33 (11). 
lacionadas às empresas sociais existentes em cada Estado-membro e compatível com os conceitos jusnormativos desenvolvidos em cada ordenamento nacional.

Práticas relacionadas às empresas sociais podem ser identificadas desde a década de 70 do século passado, mas a existência da empresa social como conceito surgiu mais tarde, já o conceito jusnormativo entre os EM da UE começa a ser construído em 1991 na Itália.

Uma pergunta eventualmente feita é quando um conceito passa a ser jusnormativo. Caberá a segunda parte deste trabalho responder a esta pergunta, explicando o processo de construção deste conceito, ou seja, a engenharia da construção dos conceitos jusnormativos.

\section{A ENGENHARIA DA CONSTRUÇÃO DOS CONCEITOS JUSNORMATIVOS}

\subsection{Os conceitos jurídicos diferem dos conceitos das outras ciências?}

O direito, diferentemente de outras áreas do conhecimento, como a medicina e a matemática, não possui uma linguagem técnica própria. Em geral, as palavras e expressões utilizadas em textos jurídicos são as mesmas palavras presentes nas conversas corriqueiras e textos jornalísticos. Apesar desta familiaridade com as palavras e expressões, pessoas leigas costumam ter a impressão de não entenderem os textos jurídicos. Isto porque o direito cria sua própria linguagem e, mesmo que use um termo comum corriqueiro ou pertencente a outra área, este pode representar um conceito diferente ${ }^{39}$.

Um exemplo desta situação pode ser a palavra vara. Vara, em uma conversa corriqueira, serve, provavelmente, para identificar um "pau comprido e fino"; já em um texto jurídico serve para identificar "cada uma das circunscrições judiciais, de competência específica e presididas por um juiz de direito, em que se dividem certas comarcas" ${ }^{\$ 4}$. Logo, um mesmo termo, dois conceitos diferentes.

Um exemplo de palavra em comum com outra área, é código. Para o direito, código serve para identificar um "conjunto ordenado de disposições, normas, preceitos, que regulam uma matéria jurídica"; já para a linguística nomeia um "sistema de relações estruturadas entre signos ou conjuntos de signos" ${ }^{\prime \prime 1}$. Mais uma vez, mesma palavra, conceitos diferentes.

\footnotetext{
39 POSCHER, R. «The Hand of Midas: When Concepts Turn Legal, or Deflating the Hart-Dworking Debate», in J. C. Hage \& D. von der Pfordten (eds.), Concepts in Law, Springer, 2009.

40 Infopédia Dicionário Portos Editora (n.d). Vara. Consultado em 28 jun. 2021. Disponível em: https://www.infopedia.pt/dicionarios/lingua-portuguesa/vara.

${ }^{41}$ Infopédia Dicionário Portos Editora (n.d.). Consultado em 28 jun. 2021. Disponível em: https:// www.infopedia.pt/dicionarios/lingua-portuguesa/código.
} 
Para Poscher ${ }^{42}$ o que ocorre nesses casos é que os termos possuem extensão e intensão diferentes e, por isso, são conceitos diferentes. Podem ocorrer casos, contudo, nos quais os termos possuem a mesma extensão, mas não a mesma intensão. Nesses casos, o conceito é compartilhado, mas possui diferentes conceções entre as diversas áreas. As exigências pragmáticas do direito provocam a necessidade do surgimento de uma conceção específica de forma a atender suas peculiaridades e suas condições diferentes de uso. Diferentes conceções podem ocorrer não somente entre áreas diferentes, mas dentro do próprio direito, entre suas especialidades ou entre ordenamentos jurídicos diferentes.

Este é o caso da expressão empresa social, além de presente nas conversas corriqueiras e nos discursos de diferentes áreas, é formada por palavras que isoladamente também são muito frequentes nestas situações, mas ao ser introduzida no discurso jurídico ganha um novo significado, que pode variar entre os diferentes ordenamentos jurídicos.

$\mathrm{O}$ direito compartilha o conceito de empresa social com outras áreas, especialmente a economia e a sociologia. Mais do que compartilhar, o direito parte das conceções destas outras áreas para desenvolver sua própria. Uma das conceções mais influentes é a desenvolvida pela EMES. A conceção da EMES resultou de um projeto teórico e empírico, fruto de um diálogo entre várias áreas do conhecimento (economia, sociologia, ciência política e administração) e as diversas práticas e tradições locais dos EM, e privilegiou a identificação e a explicitação de indicadores sobre uma definição conceitual ${ }^{43}$.

Os indicadores foram divididos em três conjuntos de acordo com três dimensões: (i) económica e empreendedora; (ii) social; (iii) gestão participativa. $\mathrm{Na}$ primeira estão os seguintes indicadores: atividade contínua de produção de bens ou serviços; nível significativo de risco económico; nível mínimo de emprego remunerado. Na segunda estão: objetivo explícito de serviço à comunidade; origem baseada em uma iniciativa coletiva; distribuição limitada de lucros. Já na terceira estão: alto grau de autonomia; poder decisório dos membros não baseado na propriedade do capital; natureza participativa com envolvimento de diferentes atores. Como são indicadores e não condições, a prática económica produtiva analisada não precisa de reunir todos eles para ser considerada uma empresa social $^{44}$.

${ }^{42}$ POSCHER, R. «The Hand of Midas: When Concepts Turn Legal, or Deflating the Hart-Dworking Debate», in J. C. Hage \& D. von der Pfordten (eds.), Concepts in Law, Springer, 2009, 1 Concepts and Conceptions.

${ }^{43}$ DEFOURNY, J. «Empresa social», Dicionário Internacional da Outra Economia, coord. de A. D. Cattani, J.-L. Laville, L. I. Gaiger, \& P. Hespanha, Almedina, Coimbra, 2009, pág. 188-192 (189).

${ }_{44}$ DEFOURNY, J., \& NYSSENS, M., The EMES Approach of Social Enterprise in a Comparative Perspective. EMES European Research Network, WP (Vol. 12), 2012, pág. 12-15. 


\subsection{Conceitos jusnormativos são conceitos jurídicos?}

Primeiramente, deve-se esclarecer que conceito jusnormativo não é sinônimo de conceito jurídico. Conceitos jusnormativos são um tipo de conceito jurídico.

Definir o que seja um conceito jurídico pode ser uma tarefa bem intricada, uma vez que praticamente qualquer conceito pode ser um conceito jurídico se ele for expresso em uma lei ou em outro material jurídico, para simplificar pode-se dizer que conceitos jurídicos são os que geralmente se encontram nos glossários do tipo padrão para estudantes de direito ${ }^{45}$.

$\mathrm{Na}$ teoria do direito existem várias abordagens sobre os conceitos jurídicos propostas por diferentes teóricos. Os estudos sobre os conceitos jurídicos apresentam diferentes perspetivas, podem abordar os seus diferentes tipos; as suas funções; a sua importância para o direito; as suas características; assim como o seu processo de formação.

Este trabalho optou pela expressão conceito jusnormativo porque quer deixar bem claro o âmbito de sua pesquisa. Jus, porque é uma pesquisa realizada no âmbito do direito, e normativo, porque busca o conceito de empresa social em um conjunto de normas jurídicas.

Para a compreensão do que sejam os conceitos jusnormativos para este trabalho, pode ser útil diferenciá-los do que poderia ser chamado conceitos jusdogmáticos. A maior diferença entre eles é que, enquanto o conceito jusnormativo é um conceito dependente, isto é, tem sua existência e seu significado condicionados a um ordenamento jurídico; o conceito jusdogmático, ao contrário, busca ser independente, busca se aproximar de um modelo ideal, é formado com base em alguma teoria do direito, e tem a pretensão de ser utilizado em diferentes ordenamentos jurídicos.

Pode-se certamente além de estudar o conceito jusnormativo, estudar também o conceito jusdogmático de empresa social. Os conceitos jusdogmáticos também são importantes para o direito, as limitações temporais e espaciais não permitem, no entanto, a inclusão do estudo destes conceitos no trabalho. Alguns conceitos jusdogmáticos podem, eventualmente, ser relevantes para a construção do conceito jusnormativo quando por exemplo, forem expressamente usados como referências em algum texto oficial.

\subsection{Quando um conceito se converte em um conceito jusnormativo?}

Pode-se dizer que o discurso jurídico está para o conceito jurídico assim como Midas está para o ouro. Se um objeto tocado por Midas se transforma em

\footnotetext{
45 FRÄNDBERG, A. (2009). «An Essay on Legal Concept Formation», in J. C. Hage \& D. von der Pfordten (eds.), Concepts in Law, Springer, 2009, 1 Introduction.
} 
ouro, uma palavra utilizada no discurso jurídico passa a expressar um conceito jurídico ${ }^{46}$.

No caso do conceito jusnormativo, mais especificamente, é a norma jurídica que está para ele como Midas está para o ouro. Se um objeto tocado por Midas se transforma em ouro, uma palavra utilizada em uma norma jurídico passa a expressar um conceito jusnormativo.

$\mathrm{O}$ entendimento do conceito jusnormativo adotado neste trabalho calha muito com a definição de conceitos jurídicos (legal concepts) de Sartor ${ }^{47}$, para ele conceitos jurídicos:

são normalmente encontrados no contexto das normas jurídicas, e a questão de determinar seu conteúdo não pode ser separada da questão de identificar e interpretar (ou construir) as normas em que ocorrem, e de usar tais normas em inferência jurídica. Consequentemente, pode-se argumentar que um sistema jurídico dota seus conceitos de significado exatamente ao incorporar tais conceitos (os termos que os expressam) dentro de certas normas jurídicas. Em vez de assumir que os termos jurídicos têm um significado prévio independente, segundo o qual devemos determinar o significado das normas que os contêm, devemos nos concentrar nas normas que contêm tais termos e nas inferências que eles permitem, e consequentemente determinam os conteúdos conceituais que tais termos pretendem transmitir ${ }^{48}$.

Esta definição de conceito jurídico está em consonância com o que este trabalho prefere chamar de conceito jusnormativo porque está de acordo com a compreensão do direito como uma prática argumentativa. Ser uma prática argumentativa faz com que os conceitos jurídicos, assim como o próprio conceito de direito, sejam conceitos interpretativos, o que significa em outras palavras que os concei-

${ }^{46}$ POSCHER, R. «The Hand of Midas: When Concepts Turn Legal, or Deflating the Hart-Dworking Debate», in J. C. Hage \& D. von der Pfordten (eds.), Concepts in Law, Springer, 2009, 3 The Midas Quality of the Law.

47 SARTOR, G. «Understanding and Applying Legal Concepts: An Inquiry on Inferential Meaning», in J. C. Hage \& D. von der Pfordten (eds.), Concepts in Law, Springer, 2009, 1 Legal Concepts and Legal Inference.

${ }^{48}$ Tradução livre de: "Legal concepts are typically encountered in the context of legal norms, and the issue of determining their content cannot be separated from the issue of identifying and interpreting (or constructing) the norms in which they occur, and of using such norms in legal inference. Consequently, it can be argued that a legal system endows its concepts with meaning exactly by embedding such concepts (the terms expressing them) within certain legal norms. Rather than assuming that legal terms have a prior independent meaning, according to which we should determine the meaning of the norms containing them, we should focus on the norms containing such terms and on the inferences they enable, and consequently determine the conceptual contents that such terms are meant to convey". 
tos jurídicos não são dados, mas sim são construídos no desdobrar da própria prática $^{49}$.

\subsection{A UE já possui um conceito jusnormativo de empresa social?}

Considerando o que foi afirmado até aqui, sim, a UE possui um conceito jusnormativo de empresa social, afinal ela já incorporou o termo empresa social em certas normas jurídicas. A pergunta ainda não respondida é qual é este conceito, afinal a UE ainda não regulou diretamente a empresa social. Caso a UE tivesse regulado diretamente a empresa social europeia, o conceito jusnormativo estaria claramente definido e, possivelmente, se enquadraria em um dos tipos adotados pelos EM, um novo tipo legal ou um novo status legal. O que não impediria a existência dos conceitos jusnormativos de empresa social próprios dos EM.

$\mathrm{O} \mathrm{PE}$ menciona, estre as disposições legais existentes na UE relacionadas à empresa social, o Regulamento (CE) 1435/2003 do Conselho de 22 de Julho de 2003 relativo ao Estatuto da Sociedade Cooperativa Europeia (SCE), apesar deste não conter as expressões empresa social ou empresas sociais. O PE relata ainda que as propostas da Comissão sobre o Estatuto das Sociedades Mútuas Europeias de 2006 e a proposta de regulamento de 2012 sobre o Estatuto da Fundação Europeia $(\mathrm{EF})$ foram retiradas, uma vez que não receberam apoio suficiente. Destaca então a iniciativa sobre um Estatuto das Empresas Sociais e Solidárias como uma oportunidade para estabelecer uma base jurídica mais ampla, tendo lançado para isto uma iniciativa própria. A Resolução do Parlamento Europeu, de 5 de Julho de 2018, que contém recomendações à Comissão sobre um Estatuto para as Empresas Sociais e Solidárias (2016/2237(INL)) (P8_TA(2018)0317), reconheceu a diversidade e o caráter inovador das formas jurídicas existentes de empresas sociais e convidou a Comissão a introduzir um "rótulo europeu da economia social", que pode ser obtido pelas empresas sociais, opcionalmente mediante pedido e ao cumprir um conjunto de critérios, independentemente da forma jurídica prevista na legislação nacional ${ }^{50}$.

A tendência da UE é então adotar um conceito jusnormativo de empresa social da espécie status legal. Até porque as suas iniciativas legislativas para regular a empresa social não poderiam assumir a forma de diretivas de harmonização. Isto porque desde as tentativas de elaboração de diretivas no direito das sociedades, os EM assumiram uma atitude cada vez mais negativa em relação à harmonização de cima para baixo. Apesar desta atitude, a introdução de um estatuto jurídico

\footnotetext{
49 DWORKIN, R. O Império do Direito. Martins Fontes, São Paulo, 2003.

50 European Parliament (EP) (2021), Legislative Train 09.2021 - Statute for social and solidarity-based enterprises, 2021. Consultado em 4 out. 2021. Disponível em: https://www.europarl.europa.eu/ legislative-train/theme-deeper-and-fairer-internal-market-with-a-strengthened-industrial-base-services-including-transport/file-statute-for-social-and-solidarity-based-enterprises.
} 
específico da UE para as empresas sociais seria um resultado desejável, embora isto pareça um pouco difícil no momento ${ }^{51}$.

\subsection{Como determinar o conceito jusnormativo europeu de empresa social?}

No contexto visto, a única forma de conhecer o conceito jusnormativo europeu de empresa social é por meio da identificação e da interpretação das normas europeias que contém o termo empresa social. Os conteúdos conceituais serão determinados a partir das inferências permitidas pelos usos do termo empresa social nos textos normativos identificados. Para isto, o primeiro passo, é a realização de uma busca no EU-lex, o portal de acesso ao direito da UE, atualizado diariamente e disponível nas 24 línguas oficiais ${ }^{52}$.

A pesquisa no EUR-lex, contudo, não deverá se limitar ao termo empresa social, nem mesmo à língua portuguesa. $\mathrm{O}$ termo empresa social expressa um conceito, este conceito, por sua vez, corresponde a uma prática económica produtiva. Em última instância, o que o direito pretende regular é esta prática. Sabendose que o conceito correspondente a esta prática pode ser expresso também por outros termos, idealmente a pesquisa deveria ser realizada em todas as 24 línguas oficiais e com os termos correspondentes a esta prática usados em cada uma das comunidades que integram a UE.

Mais importante que traduzir palavras e expressões é transportar o conceito, a prática. A mesma prática ou práticas semelhantes podem ser identificadas por expressões não literalmente correspondentes em línguas diferentes. Se na transferência do debate de uma comunidade para outra, uma tradução literal for feita e a comunidade atribuir um novo conceito à expressão traduzida, o resultado poderá ser duas comunidades realizando dois debates diferentes a pensar que debatem o mesmo conceito, a mesma prática.

A transferência do debate de uma comunidade para outra ou o debate entre membros de diferentes comunidades são ainda mais complexos porque mesmo quando todos os participantes acordam quanto a um conceito, as suas conceções podem ser diferentes.

A necessidade deste tipo de pesquisa pode ser exemplificada pelo exemplo visto acima da busca feita na plataforma IATE. No caso do português, será interessante pesquisar além de empresa social, também empresa de economia social. Já no caso do inglês, será interessante pesquisar, além de social enterprise e social economy enterprise, o termo social business. Estas são as sugestões de

${ }^{51}$ FICI, A. A European Statute for Social and Solidarity-Based Enterprise: Study for the Juri Committee. European Parliament, 2017, p. 7.

52 EUR-lex - Acesso ao direito da União Europeia (n.d.). Informações sobre o EUR-lex. Acesso em 6 jun. 2021. Disponível em: https://eur-lex.europa.eu/content/welcome/about.html. 
correspondências exatas para o termo empresa social, mas ainda há indicações de correspondências não exatas, mas com resultados semelhantes, entre quais talvez valha a pesquisa do termo empresa social e solidária em português e social and solidarity-based enterprise em inglês.

A comparação entre as versões em diferentes línguas os documentos encontrados pde ampliar os termos de pesquisa, um exemplo disto é a tradução em português do título da COM(2011) 682 Final em inglês, 'Social Business Initiative - Creating a favourable climate for social enterprises, key stakeholders in the social economy and innovation', e em português 'Iniciativa de Empreendedorismo Social - Construir um ecossistema para promover as empresas sociais no centro da economia e da inovação sociais'. O que chama atenção é o fato de apesar do subtítulo deixar claro que se trata de uma iniciativa de promoção das empresas sociais, o título usa em inglês a expressão social business que foi traduzida para o português como empreendedorismo social, quando em sentido contrário seria, provavelmente, traduzido como social entrepreneurship.

Mais um exemplo do uso de diferentes expressões usadas pela UE para se referir ao conceito objeto deste estudo é a escolha da expressão para o nome do estatuto proposto pelo PE, 'Estatuto para as empresas sociais e solidárias', em português, e 'Statute for social and solidarity-based enterprises', em inglês. Neste documento, o PE afirma serem os termos empresa social e empresa solidária (social enterprise e solidarity-based enterprise) frequentemente utilizados como sinónimos, apesar de reconhecer que as empresas a que se referem nem sempre correspondem às mesmas realidades. Apesar da observação feita pelo PE, a busca na IATE pelos termos empresa solidária e solidarity-based enterprise não encontra resultados exatos, apenas correspondências não exatas nas expressões empresa social e solidária e social and solidarity-based enterprise, quais sejam as posições das línguas português e inglês, partida ou chegada. Já a busca pelas expressões empresa social e solidária e social and solidarity-based enterprise indicam também como correspondentes apenas uma a outra. A escolha do PE talvez acabe por trazer mais confusão do que esclarecimento à construção de um conceito jusnormativo já representado por tantas expressões e com tantas conceções diferentes.

É importante entender que quando se falou em identificação e interpretação das normas europeias, a expressão normas foi utilizada no sentido lato.

Sendo assim, este trabalho de identificação e interpretação precisa ser realizado no conjunto do direito derivado ou secundário, constituído pelos atos adotados pelas instituições e outras entidades da UE, o que inclui atos legislativos e não legislativos, juridicamente obrigatórios ou não, sendo considerados tanto os atos 
emanados de fontes formais, hard law, quanto o chamado soft law, formado por guidelines, recomendações, acórdãos, comunicações, ente outros ${ }^{53}$.

Este trabalho precisa ser realizado de forma tão ampla porque a UE, além de não ter adotado ainda um estatuto da empresa social, possui poucos atos legislativos $^{54}$, isto é, atos jurídicos adotados pelo processo legislativo ordinário, que fazem uso do termo empresa social. Se a análise fosse mais restrita ainda, limitando-se aos atos legislativos integralmente obrigatórios e diretamente aplicáveis em todos os EM, os regulamentos, ela envolveria apenas quatro, o Regulamento (UE) 346/2013 do Parlamento Europeu e do Conselho de 17 de abril de 2013 relativo aos fundos europeus de empreendedorismo social, o Regulamento (UE) 1296/2013 do Parlamento Europeu e do Conselho de 11 de dezembro de 2013 que cria um Programa da União Europeia para o Emprego e a Inovação Social (“EaSI”) e que altera a Decisão 283/2010/UE que estabelece um Instrumento de Microfinanciamento Europeu Progress para o Emprego e a Inclusão Social, o Regulamento (UE) 2021/523 do Parlamento Europeu e do Conselho de 24 de março de 2021 que cria o Programa InvestEU e que altera o Regulamento (UE) 2015/1017, o Regulamento (UE) 2021/1057 do Parlamento Europeu e do Conselho de 24 de junho de 2021 que cria o Fundo Social Europeu Mais (FSE+) e que revoga o Regulamento (UE) 1296/2013.

A busca por normas que contenham a expressão no plural também interessa ao trabalho, contudo as normas que possuem a expressão no singular são mais relevantes porque, em geral, estas normas costumam trazer alguma definição ou entendimento do que seja uma empresa social, como é o caso destes quatro regulamentos. Por questão de espaço, este artigo limitou-se a analisar os regulamentos que contêm a expressão no singular.

Estes quatro regulamentos usam a expressão empresa social, 3, 1, 2 e 4 vezes, respetivamente. A expressão no plural, empresas sociais, foi usada, 24, 12, 6 e 9 vezes, respetivamente. No entanto, não há correspondência entre o número de vezes que estas expressões foram usadas e o número de vezes que as expressões social enterprise e social enterprises foram usadas nas versões em inglês dos regulamentos.

O Regulamento (UE) 346/2013 em sua versão em inglês usou social undertaking $(2 \mathrm{x})$ e social portfolio undertaking $(1 \mathrm{x})$ como correspondentes ao termo empresa social usado 3 vezes na versão em português. Já social enterprises apare-

53 GORJÃO-HENRIQUES, M. Direito da União - História, Direito, Cidadania, Mercado Interno e Concorrência, Lisboa, Almedina, 2019, p. 286-291.

${ }^{54}$ Informações sobre a classificação dos atos do direito da União Europeia ver: Acesso ao direito da União Europeia (EUR-lex). Atos jurídicos. Acesso em 6 jun. 2021. Disponível em: https://eur-lex. europa.eu/collection/eu-law/legislation/recent.html. Ver também: M. GORJÃO-HENRIQUES, Direito da União - História, Direito, Cidadania, Mercado Interno e Concorrência, Lisboa, Almedina, 2019. 
ce como correspondente a empresas sociais somente 3 vezes, as demais 21 vezes em que foi usada a expressão portuguesa, a expressão correspondente foi social undertakings.

No Regulamento (UE) 1296/2013, a expressão empresa social na única vez em que é usada em português corresponde à expressão social enterprise na versão em inglês. Por sua vez, das 12 vezes em que foi usada, a expressão empresas sociais corresponde em 11 à expressão social enterprises e em uma delas à expressão social business.

No Regulamento (UE) 2021/523, a expressão empresa social foi usada 2 vezes no texto em português e na versão em inglês ambas correspondem à expressão social enterprise. Curiosamente, a expressão social enterprise aparece 6 vezes, 4 vezes a mais, na versão em inglês do regulamento. Estas 4 vezes a mais integram a expressão social enterprise finance, correspondente a financiamento de empresas sociais em 3 vezes e a financiamento do empreendedorismo social em 1 vez. Sendo assim, 3 das 6 vezes em que a expressão empresas sociais aparece ela corresponde à expressão no singular social enterprise, como parte da expressão social enterprise finance, e nas outras 3 vezes ela correspondente à expressão social enterprises.

No Regulamento (UE) 2021/1057, 3 das 4 vezes em que o termo empresa social foi usado há correspondência com o termo social enterprise, em uma delas o uso de uma expressão correspondente não foi necessário ao texto em inglês. Em relação aos termos no plural, empresas sociais e social enterprises, ambos foram usados 9 vezes de forma correspondente.

Com isto, pode-se observar o quanto sem padrão, ainda que os dois regulamentos mais recentes apontem para uma padronização, é a tradução do termo empresa social entre textos em português e inglês e que esse termo não é o único utilizado nos textos normativos da UE para exprimir o conceito representado neste trabalho por este termo. Isto porque nos regulamentos analisados encontra-se as expressões social undertaking e social undertakings como correspondente a empresa social e empresas sociais, respetivamente; social business como análogo a empresas sociais; e ainda, empreendedorismo social como correspondente a social enterprises.

Tendo sido esses resultados obtidos apenas com uma pesquisa usando os termos empresa social, empresas socais, social enterprise e social enterprises, para que a análise fique um pouco mais completa é interessante buscar também os termos social business; empreendedorismo social; empresa(s) de(a) economia social; social economy enterprise(s); e social solidarity-based enterprise(s).

O termo social business, além de ter aparecido como correspondente a empresas sociais em um dos regulamentos e de ser apontado como equivalente a empre- 
sas social pelo IATE, é também o termo que integra o título da comunicação da $\operatorname{COM(2011)~} 682$ Final na versão em inglês, Social Business Initiative, como visto.

De forma não surpreendente, além da vez em que se encontra como correspondente a empresas sociais, o termo social business aparece mais 3 vezes no Regulamento (UE) 346/2013, duas como parte do título da COM (2011) 682 Final e uma em uma frase como correspondente a empreendedorismo social.

O termo empreendedorismo social, além de ter sido usado como correspondente a social enterprise, foi também usado de forma correspondente a social business, e, ao ser buscado diretamente, aparece 246 vezes no Regulamento (UE) 346/2013 e 17 vezes no regulamento (UE) 1296/2013. Já o seu esperado correspondente em inglês, o termo social entrepreneurship aparece 252 vezes no Regulamento (UE) 346/2013 e 17 vezes no regulamento (UE) 1296/2013.

No regulamento (UE) 1296/2013, as expressões em português e inglês são usadas de forma correspondente.

Já no regulamento (UE) 346/2013, as expressões são usadas tantas vezes porque elas integram o nome dos fundos regulados por ele, fundos europeus de empreendedorismo social, em português, e European social entrepreneurship funds, em inglês - EuSEF para ambas as línguas. No texto em inglês, o termo aparece mais vezes, isto se deve em parte às diferenças de redação entre as línguas portuguesa e inglesa, pois algumas vezes em que o texto em inglês se refere aos EuSEF utilizando o seu nome completo, o texto em português não o faz. O termo empreendedorismo social é utilizado somente 5 vezes sem ser integrando o nome dos fundos, 3 delas corresponde à expressão social business, como visto, sendo 2 vezes integrando o título da $\operatorname{COM}(2011) 682$ Final e 1 vez como correspondente a empreendedorismo social; nas outras 2 vezes corresponde a social entrepreneurship. Já o termo social entrepreneurship é usado somente 2 vezes sem ser integrando o nome dos fundos, ambas correspondem ao termo em português. É possível deduzir que o termo social business, fora do título da comunicação, foi utilizado no sentido de social entrepreneurship.

Por fim, o termo em singular empresa de economia social aparece 2 vezes no Regulamento (UE) 2021/1057, já o plural, empresas da(e) economia social, aparece 3 vezes no Regulamento (UE) 2021/523 e 2 vezes no Regulamento (UE) 2021/1057. Os termos em português encontram correspondência com os termos em inglês social economy enterprise e social economy enterprises. O termo social solidarity-based enterprise(s) não aparece nenhuma vez.

Como se pode observar, nenhum dos quatro regulamentos tem por objetivo regulamentar a empresa social em si, mas sim instrumentos e programas que tem como objetivo, entre outros, a promoção do seu financiamento. Se o objetivo é a promoção do financiamento de empresas sociais, logo é necessário saber o que é empresa social. Ante a ausência de um conceito claro ou da existência de dife- 
rentes conceções, cabe ao regulamento expressar o entendimento adotado sobre o significado deste conceito e todos eles fazem isto.

$\mathrm{O}$ entendimento de empresa social adotado pelos quatro regulamentos é bem parecido, sendo que o Regulamento (UE) 2021/523 afirma adotar a aceção das disposições aplicáveis do Regulamento FSE+ para 2021-2027, no caso o Regulamento (UE) 2021/1057. Uma observação importante, o entendimento de empresa social do Regulamento (UE) 346/2013 aqui referido é o entendimento de empresa em carteira elegível e, exatamente, por se tratar da identificação das empresas elegíveis, este entendimento traz mais algumas características, bem específicas e não abordados pelos outros regulamentos.

No entendimento de todos os regulamentos, ainda que com termos e expressões diferentes, a empresa social tem como objetivo principal, definido no seu pacto social, estatutos ou qualquer outro documento que a constitua, a produção de impactos sociais quantificáveis e positivos, aos quais o Regulamento (UE) 2021/1057 acrescentou a produção, eventualmente, de impactos ambientais.

A empresa social, em todos os regulamentos, deve prestar serviços ou fornecer bens que gerem alto rendimento social ou deve utilizar um modo de produção de bens ou serviços que concretiza o seu objetivo social. O Regulamento (UE) 346/2013 teve seu texto original alterado pelo Regulamento (UE) 1991/2017, inicialmente o texto afirmava que a empresa social deveria prestar serviços ou fornecer bens para pessoas vulneráveis, marginalizadas ou excluídas, visando o alargamento da definição de impacto social a fim de ultrapassar divergências de interpretação sobre o que constituiria um impacto social positivo nos diferentes contextos dos EM, o texto foi alterado para serviços ou bens que gerem um rendimento social. Para o Regulamento (UE) 346/2013 também será considerada empresa social a empresa que fornecer apoio financeiro unicamente a empresas sociais, sendo estas aquelas atenderem aos critérios anteriores fixados pelo regulamento, isto é, prestarem serviços ou fornecerem bens que gerem um rendimento social ou que utilizem modos de produção que concretizem o seu objetivo social.

Em relação aos lucros, para todos os regulamentos, a empresa social deve utilizá-los de acordo com procedimentos e regras que determinem a distribuição destes de forma a garantir que esta distribuição não comprometa o seu objetivo principal e que ela use seus lucros, para acima de tudo, atingir o seu objetivo principal. A diferença é que o Regulamento (UE) 2021/1057 deixou de mencionar expressamente acionistas e proprietários como destinatários da distribuição de lucros.

Sobre a gestão, todos os regulamentos mencionam uma gestão responsável e transparente, designadamente através da participação de trabalhadores, clientes e partes interessadas afetadas pelas atividades da empresa. A diferença está na 
forma empreendedora incluída pelo Regulamento (UE) 1296/2013, modificado para espírito empresarial e forma participativa no Regulamento (UE) 2021/1057.

Uma diferença que chama a atenção é a menção aos documentos constitutivos da empresa social. Para o Regulamento (UE) 346/2013, estes documentos podem ser o pacto social, estatutos ou qualquer outro regulamento interno ou documento constitutivo da sociedade. Na versão em português, há uma referência à sociedade, embora a versão em inglês não seja tão específica. O Regulamento (UE) 1296/2013 substituiu a menção a sociedade por qualquer outro documento legal que constitua a empresa social. Já o Regulamento (UE) 2021/1057 preferiu qualquer outro documento legal que possa resultar na imputação de responsabilidades segundo as regras do Estado-Membro onde uma empresa social esteja situada.

Uma outra diferença é que os regulamentos foram ficando mais expressos quanto à aceitação de variadas formas legais para a empresa social. Enquanto o Regulamento (UE) 346/2013 nada trazia, o Regulamento (UE) 1296/2013 afirma ser a empresa social "uma entidade, seja qual for a sua forma jurídica" e o Regulamento (UE) 2021/1057 vai além, ao admitir inclusive pessoas singulares.

A menção aos documentos constitutivos da empresa social é importante porque ela é um indicativo da forma jurídica desta e, portanto, de uma conceção do conceito de empresa social. Mencionar expressamente sociedade é um indicativo de uma conceção de empresas sociais que admite entre suas formas, a de sociedade. Esta conceção pode divergir de uma que considere que empresas sociais devem ter como forma legal uma das formas das entidades da economia social e exclua as sociedades desta. Já a menção à possibilidade de pessoas singulares serem reconhecidas como empresa social é indicativo da conceção de um conceito jusnormativo da espécie status legal.

O entendimento do Regulamento (UE) 2021/1057 parece querer salientar o respeito à diversidade de opções políticas, económicas e sociais, assim como a capacidade de inovação dos empresários sociais, existentes entre os EM, seguindo a orientação da IES que justifica com este respeito a não adoção de um uma definição normativa de empresa social.

Apesar dos regulamentos trazerem entendimentos sobre a empresa social, isso não dispensa a necessidade de se analisar o uso do termo ao longo do texto, uma vez que este pode, às vezes, não ter o mesmo sentido do entendimento adotado pelo regulamento, principalmente quando utilizado nos considerandos do regulamento que costumam trazer referências a outros documentos. É a partir da leitura e da interpretação de todo o texto normativo que se poderá identificar a conceção de empresa social de cada documento, para depois se poder identificar a conceção do ordenamento jurídico.

$\mathrm{O}$ que o entendimento de todos os regulamentos tem em comum é parecer seguirem a mesma linha da IES, que apesar de não ter adotado uma definição 
normativa, propôs uma descrição de forma a respeitar, o que pode ser considerado por este trabalho, as diferentes conceções do conceito normativo de empresa social dos EM.

A questão é que a depender do objeto do regulamento, este pode não servir igualmente a todas estas conceções ainda que no seu entendimento tenha incluído todas elas. Este parece ser o caso do Regulamento (UE) 346/2013 que regulamentou os EuSEF. Tais fundos assemelham-se aos fundos de capital de risco, instrumentos típicos do investimento em capital de risco, tradicional meio de investimento para as empresas capitalistas constituídas sob a forma de sociedades comerciais. Algumas das formas admitidas para a empresa social, especialmente aquelas adotadas por entidades típicas da economia social, não permitem a negociação de participações no capital, ou sequer possuem capital social, e, portanto, não poderão se beneficiar deste tipo de financiamento para as suas atividades.

Apesar de não servir igualmente a todas as formas legais de empresa social, a regulamentação dos fundos não restringe o conceito jusnormativo europeu de empresa social, porque trata apenas da regulamentação de um tipo de investimento em empresas sociais, outros instrumentos de investimento poderiam ter sido ou ainda poderão ser regulamentados de forma a beneficiar outros tipos de empresa social. Sendo assim, cada regulamento poderia adotar entendimentos mais específicos de empresa social, de acordo, com o instrumento ou programa regulamentado.

A partir da leitura dos regulamentos, é possível observar que a principal referência para os entendimentos adotados, é a IES, uma comunicação, um ato sem efeitos jurídicos obrigatórios. Isto demonstra a importância da análise de todos os atos adotados pelas instituições e outras entidades da UE, atos legislativos e não legislativos, juridicamente obrigatórios ou não, emanados de fontes formais, hard law ou soft law.

As comunicações, inclusive, de acordo com entendimento do Tribunal de Justiça da UE, mesmo sendo atos atípicos e sem efeitos jurídicos obrigatórios, vinculam a própria Comissão e seus elementos devem ser considerados pelos intérpretes do Direito da UE ${ }^{55}$.

O conceito jusnormativo de empresa social trata-se de um conceito em construção ${ }^{56}$, porque, como visto, a cada novo documento, novos elementos são in-

55 GORJÃO-HENRIQUES, M. Direito da União - História, Direito, Cidadania, Mercado Interno e Concorrência, Lisboa, Almedina, 2019, pág. 321.

56 Kähler prefere usar a expressão formação de conceito ao invés de construção de conceito, porque a expressão construção de conceito parece um processo consciente, algo que nem sempre ocorre em relação aos conceitos jurídicos (KÄHLER, Lorenz. « The influence of normative reasons on the formation of legal concepts », in J. C. Hage \& D. von der Pfordten (eds.), Concepts in Law, Springer, 2009). 
cluídos no conjunto dos elementos que o constituem, o que leva a alterações na conceituação final do termo.

$\mathrm{Na}$ análise dos regulamentos, alguns elementos do conceito de jusnormativo de empresa social foram destacados. Alguns deles, como forma jurídica, objetivo, distribuição de lucros, modos de organização e gestão, são expressos no entendimento de empresa social adotado pelos regulamentos. Outros, como as características dos instrumentos e dos programas regulamentados também são importantes, porque podem beneficiar ou mais ou menos uma ou outra conceção de empresa social e assim indicar a preferência ou valorização de uma determinada conceção.

\subsection{Quais são os elementos relevantes para o conceito jusnormativo de empresa social?}

Os aqui chamados conceitos jusnormativos encontram correspondência com o que Sartor ${ }^{57}$ classifica como conceitos normativos intermediários que são "aqueles conceitos através dos quais as normas jurídicas transmitem consequências jurídicas e pré-condições para efeitos jurídicos adicionais" ${ }^{58}$. Neste sentido, os conceitos normativos são entendidos como estruturas inferenciais. Se determinadas condições estão presentes então haverá as consequências previstas ( if - then).

O conceito jusnormativo de empresa social é um conceito normativo intermediário. As normas de Direito da UE, que trazem o termo empresa social, buscam estabelecer as condições para o seu reconhecimento e as consequências deste reconhecimento. Tanto a regulação das empresas sociais quanto o incentivo a elas não prescindem de uma conceção do que se quer regular e do que se quer incentivar, no caso, a empresa social.

O desenvolvimento da regulação da empresa social pressupõe uma sequência de regras inferenciais. Primeiro a que determina as condições necessárias para uma atividade ser considerada empresa social e em seguida, o reconhecimento como empresa social passa a ser a condição para as consequências estabelecidas.

Assim, os primeiros elementos que devem ser identificados são aqueles que determinam as condições para o reconhecimento da empresa social e que aparecem, de certa forma, nos entendimentos dos regulamentos. São eles: forma jurídica; objetivos; regras sobre busca e distribuição de lucros; forma de gestão; fontes de receitas.

57 SARTOR, G. «Understanding and Applying Legal Concepts: An Inquiry on Inferential Meaning», in J. C. Hage \& D. von der Pfordten (eds.), Concepts in Law, Springer, 2009, 1 Legal Concepts and Legal Inference.

58 Tradução livre de: “(...) those concepts through which legal norms convey both legal consequences and preconditions of further legal effects (...)." 
De certa forma, estes elementos encontram correspondência com os indicadores da conceção desenvolvida pela EMES, tendo apenas sido adaptados de forma às exigências a atender suas peculiaridades e suas condições diferentes de uso.

Como condições, esses elementos podem ser classificados como necessários ou suficientes ${ }^{59}$. Um elemento é uma condição necessária quando sem ele não há o reconhecimento de uma empresa social. Um elemento é uma condição suficiente quando a existência dele é o suficiente para o reconhecimento de uma empresa social. Por exemplo, a forma legal poderia ser uma condição suficiente se for a única a ser exigida. Agora, se junto a ela forem exigidos outros elementos como limites à distribuição de lucros e gestão de democrática, por exemplo, cada um destes elementos é uma condição necessária e todos conjuntamente compõem uma condição suficiente. Como no caso da empresa social vários são os elementos analisados, é preciso levar em consideração também a possibilidade de diferentes combinações serem suficientes para o reconhecimento de uma empresa social.

Dentre os elementos para o reconhecimento da empresa social, é importante conhecer como estes elementos serão constatados quando ser uma empresa social for uma condição para alguma consequência, como participação em um programa. Na ausência de um registo ou status europeu é importante saber a quem caberá o dever de verificação destes nos casos de cada instrumento e programa de financiamento das empresas sociais.

Como a UE ainda não regulamentou expressamente as empresas sociais, estes elementos e sua classificação são identificados de forma indireta.

Como visto, a UE já possui instrumentos e programas de financiamento. De certa forma, apesar de estes regulamentos criarem consequências para a condição de empresa social, eles também contribuem para o desenvolvimento do próprio conceito normativo de empresa. Fazem isto, não somente ao trazerem seu entendimento sobre estas, mas também porque ao estabelecerem instrumentos e programas de incentivo e financiamento, as características destes, por serem mais compatíveis com um ou outro formato de empresa social, indicam a conceção adotada pelo ordenamento europeu.

Cada novo ato, que traz o termo empresa social, incluído no ordenamento jurídico europeu deve ser analisado porque cada mudança na rede normativa determina imediatamente mudanças conceituais ${ }^{60}$.

Caso a Comissão introduza um rótulo europeu da economia social para ser atribuído às empresas sociais seguindo a sugestão do PE, prevista na Resolução

59 PFORDTEN, D. von der. «About concepts in Law», in J. C. Hage \& D. von der Pfordten (eds.), Concepts in Law, Springer, 2009, 4 Conceptual Analysis.

${ }^{60}$ SARTOR, G. «Understanding and Applying Legal Concepts: An Inquiry on Inferential Meaning», in J. C. Hage \& D. von der Pfordten (eds.), Concepts in Law, Springer, 2009, Cap. 3 - 1 Legal Concepts and Legal Inference. 
P8_TA(2018)0317, a forma jurídica não será provavelmente uma condição suficiente, nem mesmo uma condição necessária. Isto porque os requisitos legais para a sua atribuição deverão ser previstos independentemente da forma jurídica da empresa social constituída em um EM. Para facilitar a identificação das formas jurídicas que poderão receber o rótulo, o PE exorta a Comissão, em cooperação com os EM, a elaborar uma lista das formas jurídicas existentes nos EM que tenham as características das empresas sociais e a manter essa lista atualizada de forma a respeita as especificidades históricas e jurídicas de cada EM.

Os requisitos previstos pelo PE na Resolução P8_TA(2018)0317 para a concessão do rótulo são semelhantes aos indicadores da conceção da EMES e também aos elementos identificados por este trabalho para a empresa social: a organização deve ser uma entidade privada, constituída sob uma das formas admitidas pelos EM; o seu objeto deve ser essencialmente de interesse geral e/ou de utilidade pública; deve realizar essencialmente uma atividade de utilidade social e solidária; deve ser objeto de restrições, pelo menos parciais, em matéria de distribuição de lucros e de regras específicas sobre a afetação dos lucros e ativos durante todo o seu ciclo de vida, incluindo no momento da sua dissolução; deve ser gerida de acordo com modelos de governação democrática e os poderes dos membros no processo de decisão não devem basear-se no capital que possam deter.

Fazendo uma breve associação entre os elementos identificados por este trabalho e os requisitos do PE para a empresa social, pode-se dizer: a forma jurídica seria qualquer uma admitida pelos EM; os objetivos devem ser essencialmente sociais; as regras sobre busca e distribuição de lucros devem impor restrições; a gestão deve ser democrática; não há um correspondente para as fontes de receitas.

\subsection{Qual a aplicabilidade de um conceito jusnormativo europeu de empresa social?}

O destaque dado às normas até aqui pode parecer reduzir o direito a normas, o que Pfordten ${ }^{61}$ considera um reducionismo fundamental. Para ele, os conceitos têm um papel principal no direito, maior do que as normas, e uma das razões deste reducionismo está relacionada com o nominalismo. Para o nominalismo os conceitos seriam apenas unidades de linguagem representacionais, ou seja, palavras ou conexões de palavras ou partes similares dos sistemas de linguagem de representação. Mas se fosse assim, os conceitos seriam tão contingenciais como as palavras são. $\mathrm{O}$ autor reforça sua crítica ao afirmar que diferentes palavras em diferentes linguagens são conectadas no entendimento com um conceito.

${ }^{61}$ PFORDTEN, D. von der. «About concepts in Law», in J. C. Hage \& D. von der Pfordten (eds.), Concepts in Law, Springer, 2009, 3 What Are Concepts. 
Pfordten propõem uma forma diferente de classificar os conceitos jurídicos, ele não os diferencia entre dogmáticos e jusnormativos como visto neste trabalho. Sua classificação é em níveis e estes níveis variam de acordo com critérios de abstração e contingência. Quanto menos abstrato e mais contingente for um conceito, mais possibilidades há para a determinação deste conceito por meio de normas legais até ao extremo da total invenção, o que não é possível com conceitos mais abstratos que precisam manter uma conexão com o esquema conceitual geral, com o mundo não jurídico ${ }^{62}$.

A forma de classificar os conceitos jurídicos e as críticas do autor não são incompatíveis com a conceção de conceito jusnormativo deste trabalho. Ao contrário, este trabalho reforça a importância dos conceitos para o direito. Apesar de afirmar que um conceito se torna jusnormativo quando um termo que o representa é incluído em uma norma jurídica, isto não significa que este seja uma invenção do ordenamento jurídico. Considerando a classificação de Pfordten baseada em critérios de abstração e contingência, pode-se afirmar que o conceito de empresa social é mais abstrato e menos contingente do que o conceito de sociedade de responsabilidade limitada, por exemplo. Isto porque o conceito jusnormativo de empresa social precisa manter uma conexão com o mundo não jurídico, no caso, as práticas económicas produtivas assim identificadas pelas diferentes comunidades.

O conceito jusnormativo de empresa social não tem sentido apenas no contexto de um ato normativo, mas também no contexto das diferentes comunidades, comunidades mais universais como a UE, e também particulares, como os EM. Se os textos normativos indicarem mais de um sentido, deve-se privilegiar o sentido mais compatível com a comunidade. Se o conceito final não refletir às práticas e princípios da comunidade, tanto o conceito normativo quanto as normas do qual ele foi extraído tendem a ineficácia. Isto porque o conceito jusnormativo até existirá, determinado pela interpretação das normas onde os termos correspondentes ao conceito tiverem sido utilizados, mas não será aplicável porque as condições necessárias não serão encontradas no mundo.

A UE deve-se preocupar não somente em possuir um conceito jusnormativo de empresa social, mas também com a aplicabilidade deste conceito. Até o momento, a UE parece estar se preocupando em possuir um conceito jusnormativo de empresa social que respeite as diferentes conceções dos EM. A questão é que o caminho escolhido pode não ser o mais adequado. Isto porque os elementos caracterizados da empresa social têm sido colocados de forma muito ampla, enquanto os instrumentos e programas criados não acompanham esta amplitude. Além disso, resta verificar se os elementos considerados necessários para a empresa social são compatíveis entre si e mais do que isso, compatíveis com as conceções dos EM.

\footnotetext{
62 PFORDTEN, D. von der. «About concepts in Law», in J. C. Hage \& D. von der Pfordten (eds.), Concepts in Law, Springer, 2009, 6 Concepts in Law.
} 


\section{CONSIDERAÇÕES FINAIS}

O objetivo deste trabalho foi destacar a importância do conceito jusnormativo europeu de empresa social para a regulação desta. A UE espera promover e incentivar a empresa social entre os EM. O sucesso desta empreitada depende, como ela sabe, do respeito às práticas e aos ordenamentos jurídicos dos EM.

O processo de construção do conceito jusnormativo de empresa social, ou processo de formação, uma vez que talvez não seja um processo tão consciente, é complexo. Isto porque vai além da conceituações expressas em atos legislativos, mas inclui todas as menções ao conceito que se pretende regular no conjunto do direito derivado ou secundário, constituído pelos atos adotados pelas instituições e outras entidades da UE, o que inclui atos legislativos e não legislativos, juridicamente obrigatórios ou não, sendo considerados tanto os atos emanados de fontes formais, hard law, quanto o chamado soft law, formado por guidelines, recomendações, acórdãos, comunicações, ente outros. Atenção para o fato de que se deve buscar todas as menções ao conceito e não ao termo empresa social porque o que se pretende regular é o conceito, a prática, que pode ser representada por diversos termos, como visto, e não somente empresa social. O que é ainda maior no caso da UE devido ao fato de ser uma comunidade formada por diferentes comunidades, com línguas e práticas diferentes.

O conceito jusnormativo de empresa social é um conceito em construção porque como todos os conceitos jusnormativos, a cada nova menção em um ato normativo, novos elementos são incluídos no conjunto dos elementos que o constituem, o que leva a alterações na conceituação final do termo.

Os conceitos normativos são entendidos como estruturas inferenciais. O desenvolvimento da regulação da empresa social, portanto, pressupõe uma sequência de regras inferenciais. Primeiro a que determina as condições necessárias para uma atividade ser considerada empresa social e em seguida, o reconhecimento como empresa social passa a ser a condição para as consequências estabelecidas. A UE parece, no entanto, ter iniciado esse processo ao contrário, estabelecendo primeiro consequências para as empresas sociais, como instrumentos e programas de financiamento para estas desde 2013, tendo ficado as condições para o seu reconhecimento em aberto. Desde 2018, no entanto, a partir da Resolução P8_TA(2018)0317 do PE, a UE parece caminhar para a adoção de um conceito jusnormativo da espécie status legal através da criação do rótulo europeu da economia social.

A opção da UE pela criação de um rótulo parece ser uma escolha compatível com o objetivo de respeitar as características e escolhas dos EM. Sua aplicabilidade depende, contudo, de compatibilidade não somente com as conceções dos EM, mas com a conceção de empresa social da própria EU. De forma a garantir a aplicabilidade e eficiência do conceito jusnormativo europeu de empresa so- 
cial é importante a tomada de consciência sobre o processo de construção deste conceito e a identificação do estado atual deste conceito a partir da identificação e interpretação das normas europeias que contém os termos representativos do conceito que se busca regular.

\section{Bibliografia}

\section{Doutrina}

ABREU, J. M. Coutinho de, «Empresas Sociais (Nótulas de Identificação)», CES, 37, (2015), pág. 369-376.

Americans for Community Development (n.d). Consultado em 7 de out. 2021. Disponível: https://americansforcommunitydevelopment.org/laws/.

ANAZ, S. (2014). «A inovação social aponta novos caminhos para as empresas». HSM MANAGEMENT, 103 (2014), p. 58-72.

Benefit Corporation (n.d). State by State Status of Legislation. Consultado em 7 de out. 2021. Disponível em: https://benefitcorp.net/policymakers/state-by-state-status).

CODREA-RADO, A. «European parliament has 24 official languages, but MEPs prefer English», THE GUARDIAN, (2014). Consultado em 4 jun. 2021. Disponível em: https:// www.theguardian.com/education/datablog/2014/may/21/european-parliament-englishlanguage-official-debates-data.

DEFOURNY, J. «Economia social». Dicionário Internacional da Outra Economia, coord. de A. D. Cattani, J.-L. Laville, L. I. Gaiger, \& P. Hespanha, Almedina, Coimbra, 2009, pág. 156-161.

DEFOURNY, J. «Empresa social», Dicionário Internacional da Outra Economia, coord. de A. D. Cattani, J.-L. Laville, L. I. Gaiger, \& P. Hespanha, Almedina, Coimbra, 2009, pág. 188-192.

DEFOURNY, J., \& NYSSENS, M., The EMES Approach of Social Enterprise in a Comparative Perspective. EMES European Research Network, WP (Vol. 12), 2012.

DWORKIN, R. O Império do Direito. Martins Fontes, São Paulo, 2003.

EMES - International Research Network (EMES) (n.d). Who we are. Consultado em 6 out. 2021. Disponível em: https://emes.net/who-we-are/.

European Commission (EC) (2015). A map of social enterprises and their ecosystems in Europe. Synthesis Report. Luxembourg: Publications Office of the European Union. Disponível em: https://europa.eu/!Qq64ny.

FERREIRA, S. «Terceiro sector». Dicionário Internacional da Outra Economia, coord. de A. D. Cattani, J.-L. Laville, L. I. Gaiger, \& P. Hespanha, Almedina, Coimbra, 2009, pág. 322-327.

FICI, A. A European Statute for Social and Solidarity-Based Enterprise: Study for the Juri Committee. European Parliament, 2017.

FRÄNDBERG, A. (2009). «An Essay on Legal Concept Formation», in J. C. Hage \& D. von der Pfordten (eds.), Concepts in Law, Springer, 2009. 
GORJÃO-HENRIQUES, M. Direito da União - História, Direito, Cidadania, Mercado Interno e Concorrência, Lisboa, Almedina, 2019.

HAGE, J. C. \& PFORDTEN, D. von der (eds.), Concepts in Law, Springer, 2009.

KÄHLER, Lorenz. «The influence of normative reasons on the formation of legal concepts », in J. C. Hage \& D. von der Pfordten (eds.), Concepts in Law, Springer, 2009

MEIRA, D., \& RAMOS, M. E. «Empresas sociais e sociedades comerciais: ¿realidades convergentes ou divergentes?». COOPERATIVISMO \& DESARROLLO, 27, 1 (2019), pág.1-33

NAMORADO, R. «O que é a economia social?». Economia Social em Textos, CECES, Coimbra, 2017.

PAREKH, N. 51 Questions on Social Entrepeneurship, Mountain View, Quad Press, 2015.

PFORDTEN, D. von der. «About concepts in Law», in J. C. Hage \& D. von der Pfordten (eds.), Concepts in Law, Springer, 2009.

POSCHER, R. «The Hand of Midas: When Concepts Turn Legal, or Deflating the HartDworking Debate», in J. C. Hage \& D. von der Pfordten (eds.), Concepts in Law, Springer, 2009, Cap. 7.

SARTOR, G. «Understanding and Applying Legal Concepts: An Inquiry on Inferential Meaning», in J. C. Hage \& D. von der Pfordten (eds.), Concepts in Law, Springer, 2009, Cap. 3.

\section{Atos jurídicos da União Europeia}

\section{Comunicações}

(COM(2011) 682 final) - Comunicação da Comissão ao Parlamento Europeu, ao Conselho, ao Comité Económico e Social Europeu e ao Comité das Regiões, de 25 de outubro de 2011, intitulada «Iniciativa de Empreendedorismo Social - Construir um ecossistema para promover as empresas sociais no centro da economia e da inovação sociais».

\section{Regulamentos}

Regulamento (CE) 1435/2003 do Conselho de 22 de julho de 2003 relativo ao Estatuto da Sociedade Cooperativa Europeia (SCE), JO L 207 de 18.8.2003, p. 1-24.

Regulamento (UE) 346/2013 do Parlamento Europeu e do Conselho de 17 de abril de 2013 relativo aos fundos europeus de empreendedorismo social, JO L 115 de 25.4.2013, p. 18-38.

Regulamento (UE) 1296/2013 do Parlamento Europeu e do Conselho de 11 de dezembro de 2013 que cria um Programa da União Europeia para o Emprego e a Inovação Social ("EaSI") e que altera a Decisão 283/2010/UE que estabelece um Instrumento de Microfinanciamento Europeu Progress para o Emprego e a Inclusão Social, JO L 347 de 20.12.2013, p. 238-252.

Regulamento (UE) 2021/523 do Parlamento Europeu e do Conselho de 24 de março de 2021 que cria o Programa InvestEU e que altera o Regulamento (UE) 2015/1017, JO L 107 de 26.3.2021, p. 30-89. 
Regulamento (UE) 2021/1057 do Parlamento Europeu e do Conselho de 24 de junho de 2021 que cria o Fundo Social Europeu Mais (FSE+) e que revoga o Regulamento (UE) 1296/2013, JO L 231 de 30.6.2021, p. 21-59.

\section{Resoluções}

P8_TA(2018)0317 - Estatuto para as empresas sociais e solidárias - Resolução do Parlamento Europeu, de 5 de julho de 2018, que contém recomendações à Comissão sobre um estatuto para as empresas sociais e solidárias (2016/2237(INL)).

\section{Outros documentos da União Europeia}

European Economic and Social Committee (EESC) (2014). Project on Social Enterprise Recommendations (ISBN 978-92-830-2535-1), Bruxelles.

European Parliament (EP) (2021), Legislative Train 09.2021 - Statute for social and solidaritybased enterprises, 2021. Consultado em 4 out. 2021. Disponível em: https://www.europarl. europa.eu/legislative-train/theme-deeper-and-fairer-internal-market-with-a-strengthenedindustrial-base-services-including-transport/file-statute-for-social-and-solidarity-basedenterprises.

União Europeia (UE) (n.d). As línguas da União Europeia. Consultado em 3 jun. 2021. Disponível em: https://europa.eu/european-union/about-eu/eu-languages_pt.

Comissão Europeia (CE) (2013). Memo - Perguntas frequentes sobre línguas na Europa. Consultado em 3 jun. 2021. Disponível em: https://ec.europa.eu/commission/presscorner/ detail/en/MEMO_13_825.

Interactive Terminology for Europe (IATE) (2021). Perguntas frequentes sobre a IATE. Consultado em 3 jun 2021. Disponível em: https://iate.europa.eu/faq.

\section{Legislação}

DINAMARCA (DANMARK). LOV nr 711 af 25/06/2014. https://www.retsinformation.dk/eli/ $1 \mathrm{ta} / 2014 / 711$

ESPANHA (ESPAÑA). Ley 27/1999, de 16 de julio, de Cooperativas. BOE-A-1999-15681.

FINLÂNDIA (SUOMI). Laki sosiaalisista yrityksistä 1351/2003. FINLEX. FIN- LEX, 2013. http://www.finlex.fi/fi/laki/al- kup/2003/20031351.

FRANÇA(FRANCE).Loin ${ }^{\circ}$ 2001-624du 17juillet2001 portantdiversesdispositionsd'ordresocial, éducatif et culturel (1). https://www.legifrance.gouv.fr/loda/id/LEGIARTI000006758365 /2001-07-18\#LEGIARTI000006758365

ITÁLIA (ITALIA). Legge 8 novembre 1991, n. 381. GU n.283 del 3-12-1991.

ITÁLIA (ITALIA). Decreto Legislativo 24 marzo 2006, n. 155. GU Serie Generale n.97 del 27-04-2006.

PORTUGAL. Decreto-Lei n. ${ }^{\circ} 7 / 98$ de 15 de janeiro do Ministério do Trabalho e da Solidariedade. Diário da República n. ${ }^{\circ}$ 12/1998, Série I-A de 1998-01-15.

REINO UNIDO (UNITED KINGDOM). The Community Interest Company Regulations 2005 (SI:2005/1788). https://www.legislation.gov.uk/uksi/2005/1788/contents/made 


\section{Dicionários}

Infopédia Dicionário Portos Editora (n.d). Vara. Consultado em 28 jun. 2021. Disponível em: https://www.infopedia.pt/dicionarios/lingua-portuguesa/vara.

Infopédia Dicionário Portos Editora (n.d.). Consultado em 28 jun. 2021. Disponível em: https://www.infopedia.pt/dicionarios/lingua-portuguesa/código. 